Alma Mater Studiorum - Università di Bologna DEPARTMENT OF ECONOMICS

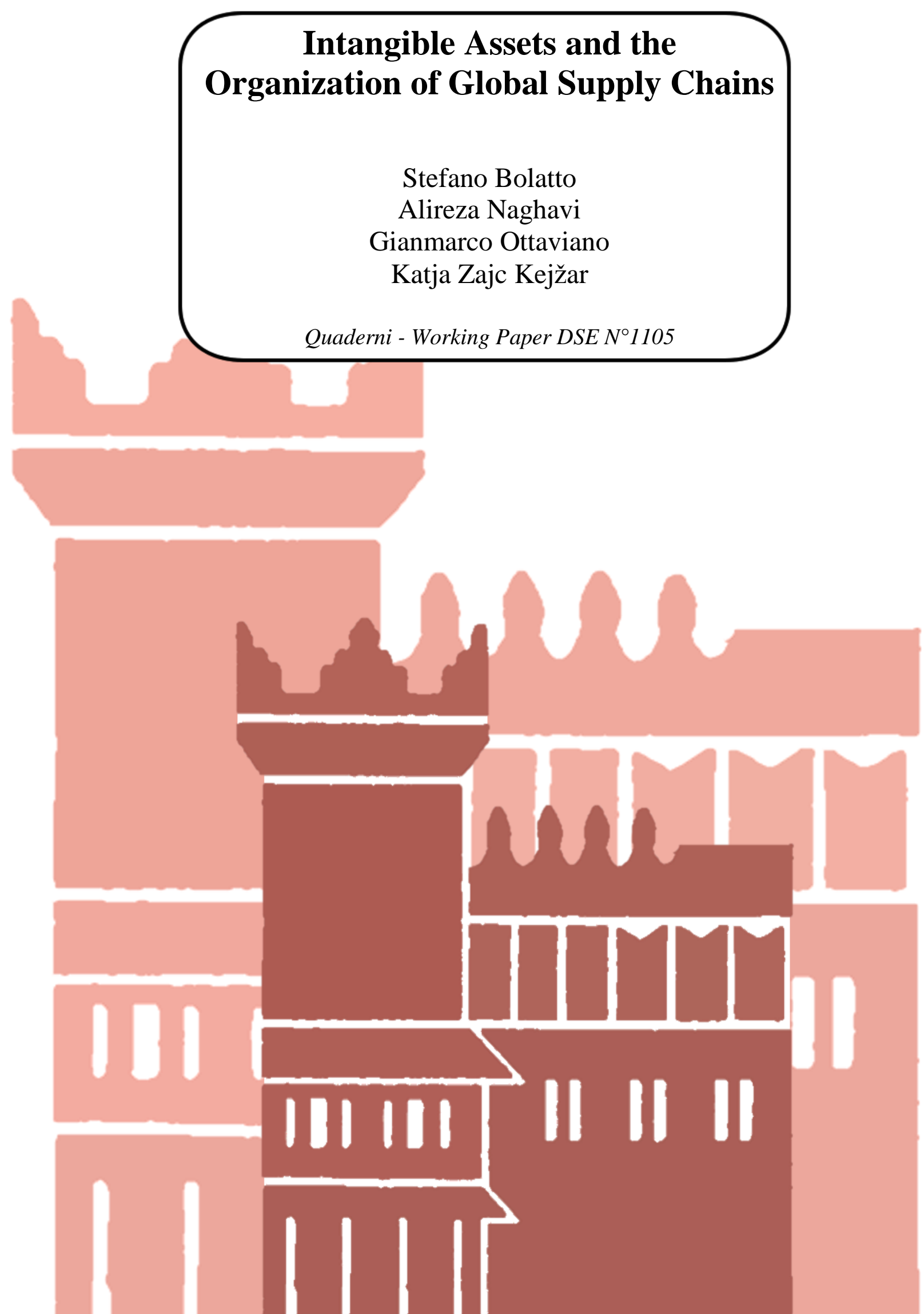




\title{
Intangible Assets and the Organization of Global Supply Chains*
}

\author{
Stefano Bolatto $^{\dagger} \quad$ Alireza Naghavi Gianmarco Ottaviano $^{\S} \quad$ Katja Zajc Kejžar $₫$
}

\begin{abstract}
This paper introduces the concept of intangible assets in sequential supply chains and the importance of their appropriability in the organizational decision of firms. We focus on the quality of intellectual property rights (IPR) institutions, which on top of the hold-up problem between a supplier and the final producer entails an additional risk of imitation as technology may leak to competing producers in the market. The level of IPR enforcement in the location of a supplier can therefore play a crucial role in determining the decision of a final good producer whether to outsource or integrate a particular stage of production. The analysis is performed with Antràs and Chor (2013) in the background, where the position of the input along the supply chain, i.e. its upstreamness, and the degree of sequential complementarity of stagespecific inputs influence the organizational strategy of firms through the incentive structure of supplier investments. Our findings show that introducing intangible assets in sequential supply chain may have the opposite effect of contractibility on outsourcing decision, where only tangible property rights are considered. We argue therefore that the risk of imitation is a relevant feature that needs to be accounted for in the incomplete contract literature. Our theoretical predictions are validated on Slovenian firm-level data.
\end{abstract}

J.E.L. Classification: F12, F14, F21, F23, D23, L22, L23, L24, O34.

Keywords: Sequential production, Intellectual property, Intangible assets, Appropriability, Stage complementarity, Upstreamness, Firm organization, Outsourcing, Integration.

\footnotetext{
${ }^{*}$ We are grateful to Carlo Altomonte, Catherine Thomas, and Gerald Willman for valuable discussions. We have also benefited from helpful comments from seminars participants at the University of Ljubljana, University of Bologna, Kindai University (Osaka), and Kyoto University, and the audience at the CompNet Annual Conference (Brussels), Australasian Trade Workshop (Brisbane), International Association for Applied Econometrics Conference (Sapporo), Asia-Pacific Trade Seminar (Hanoi), International Conference "Challenges of Europe" (Bol), and Italian Trade Study Group meeting (Bergamo).

${ }^{\dagger}$ University of Bologna, Department of Economics. Email: stefano.bolatto@unibo.it.

$¥$ University of Bologna, Department of Economics. Emai: alireza.naghavi@unibo.it.

$\S$ London School of Economics and Political Science, Department of Economics and Centre for Economic Performance, and the University of Bologna, Department of Economics. Email: g.i.ottaviano@lse.ac.uk.

๑ University of Ljubljana, Faculty of Economics. Email: katja.zajc@ef.uni-lj.si.
} 


\section{Introduction}

Modern value chains are becoming more and more global in nature, as they are increasingly characterized by the participation of suppliers located across different countries. Incomplete contracts and contract enforcement continue to be a central issue in this context when studying the integration versus outsourcing decision of firms. ${ }^{1}$ The two familiar approaches to confront the issue are the transaction cost theory (Williamson, 1971, 1975, 1985) and the property right theory (Grossman and Hart, 1986; Hart and Moore, 1990). The literature has by now established how specific features of different production locations such as contract enforcement affect the organizational decision of firms. Under the transaction cost approach, better contracting institutions reduce hold-up problems associated with outsourcing and facilitate the exploitation of specialization gains from outsourcing. With the property rights approach, better contracting institutions mitigate the need to create investment incentives through outsourcing and enable a firm to reap a larger share of the revenue through integration. Empirical studies starting from Corcos et al. (2013) all the way up to the very recent work of Eppinger and Kukharskyy (2017) have found strong evidence for the property right theory evincing that better institutional quality increases incidences of integration. There are clearly exceptions such as Defever and Toubal (2013), who for example show evidence in line with the transaction cost theory that outsourcing prevails for the most productive firms due to its relatively higher organizational costs.

This paper introduces the concept of intangible assets in supply chains and the importance of their appropriability in the organizational decision of firms. The simple question we ask is whether intangible assets are relevant for global value chains. The peculiar feature of intangible assets is that they exist as dark matter and cannot be observed. We infer the presence of intangible assets by studying whether the organizational decision of firms react to changes in the strength of intellectual property rights (IPR) protection. In other words, we exploit observable variation in the IPR regime to reveal the importance of unobservable intellectual assets and their (non-)appropriability along the value chain. The focus therefore shifts from property rights to IPRs, which on top of the hold-up problem between a supplier and the final producer entails an additional risk of imitation as technology may leak to competing producers in the market. The quality of IPR institutions in the location of a supplier could therefore play a role in determining the decision of a final good producer whether to outsource or integrate a particular stage of production. We argue that the risk of imitation is an important feature that needs to be accounted for in the incomplete contract literature. Practically all existing works on trade and firm organization have focused on the "tangible" perception of property rights and hold-up problems, compelling Antràs and Rossi-Hansberg (2009) to underline the importance of missing research on how the non-appropriable nature of knowledge may also affect

\footnotetext{
${ }^{1}$ See the vast literature on international trade and the boundaries of firms (e.g. Antràs, 2003, 2005; Antràs and Helpman, 2004, 2008; Grossman and Helpman, 2002, 2003, 2005).
} 
the internalization decision of firms.

The argument takes more importance when considering production stages along the supply chain. On this, Atalay, Hortacsu and Syverson (2014) emphasize the importance of intangible inputs within a firm by providing evidence for an alternative rationale behind vertical integration and its role in promoting efficient intra-firm transfers of intangible inputs such as marketing know-how, intellectual property, and $\mathrm{R} \& \mathrm{D}$ capital. In other words, they show, in line with the property right theory, that integration is not a tool to insure a smooth flow of physical inputs from upstream towards downstream activities, but a strategy to secure efficient transmission of technology across stages along the chain. A fundamental lesson learned from the work of Atalay, Hortacsu and Syverson (2014) is the importance of distinguishing intangible assets from tangible ones, and the critical role of firm organization in their movement along the supply chain. Our analysis takes a step in this direction, using the sequential production model of Antràs and Chor (2013) as a tool to explore the intangible dimension of firm organization.

The sequential dimension of production along the supply chain shows how the position of and the inter-relation between the stages of production impact firms' organizational decision through the structure of incentives for suppliers. If supplier investments are sequential complements, prior upstream investment by a given supplier would increase marginal returns to investment by the suppliers performing the next stages of production, whereas in the case of sequential substitutes it would reduce the marginal revenue of further investment in subsequent stages. As a result, upstream (downstream) stages are outsourced (integrated) when stages are sequential complements and integrated (outsourced) when they are sequential substitutes. This mechanism works under the property right approach, where outsourcing, i.e. giving a larger share of the pie to a supplier, encourages investment by that particular supplier. Alfaro et al. (2015) incorporate the notion of contractibility from Antràs and Helpman (2008) into Antràs and Chor (2013) and interestingly show that better relative contractibility in the upstream part of the production process tends to increase a firm's propensity to integrate in the case of sequential complementarity, whereas it increases outsourcing when stages are sequential substitutes. They argue that the intuition behind this regularity stems directly from the property right theory: "the higher the contractibility of inputs, the less firms need to rely on outsourcing as a way to reverse the distortions associated with inefficient investment by upstream suppliers."

Imitation in our framework is embedded into the property right theory, where inefficiencies caused by contract incompleteness in terms of underinvestment into relation-specific inputs are present both within firm boundaries and in arm's length transactions. In the context of sequential production, the lack of effective IPR protection at any stage of production implies a higher risk of an imitation shock, reducing profits for the final good producer as well as that of other suppliers within the chain. To elucidate the concept, think of a supply chain with each stage of production requiring a 
blueprint to be shared between the firm and the supplier. The likelihood for the blueprint at a given stage to leak outside the supply chain depends solely on the IPR environment at the production location. ${ }^{2}$ Weak IPRs increase the arrival rate of imitation similarly for all stages irrespective of their position, but moving downstream increases the probability of the supply chain being disrupted due to increased exposure of the chain to imitation. All in all, imitation decreases the value of supplier investments for the entire supply chain, ex-ante, that is at the moment when the firm decides the optimal allocation of property rights for each stage before production starts.

The paper delivers a number of clear theoretical predictions that are tested on firm-level data using a comprehensive dataset on Slovenian firms. We merge transaction-level trade data on firms together with their outward cross-border direct investment and financial data. Transaction trade data provides information on the complete set of inputs imported at the firm level, while FDI data gives the location of related subsidiaries. The firm's decision to integrate an input is estimated at the firm-country-product level. It is measured as the propensity to transact an input in a particular source country within firm boundaries, whereby we distinguish between integration and outsourcing by exploiting information on the core activity of the firm's affiliate in a particular host country. We use industry-pair specific measures of upstreamness in a manner of Alfaro et al. (2015) and identify whether stages of the value chain are sequential complements or substitutes based on import demand elasticities for each product category al Antràs and Chor (2013). In our case, we use import demand elasticities estimated for core products exported by Slovenian firms obtained from Kee, Nicita, and Olarreaga (2008) following the "production-based GDP-function" approach. We also introduce new proxies for complementarity and interdependence between stages within a supply chain by measuring the degree of inputs differentiation (the extent to which they are spread across diverse industries). Finally, the IPR enforcement index it retrieved from Park (2008).

Our findings show, in contrast to the tangible property right notion of contractibility in which stronger enforcement encourages integration and intra-firm trade, IPR protection increases propensity towards international outsourcing by final good producers. This is merely a result of the incentive structure of supply investment in sequential supply chains, and is obtained without any assumptions on imitation being specific to outsourcing. As such, our study is not a model prevention of dissipation, but one on the mitigation of its effect on profits.

This mechanism works in parallel to Antràs and Chor (2013) and Alfaro et al. (2015), with the incentive structure of supplier investment at play, producing novel results in the presence nonappropriable intangible assets. We show that the lack of the protection of intellectual property induces firms to hold on to a larger share of the revenue by opting for integration when inputs are sequential complements. This is driven by imitation creating uncertainty about the future of the

\footnotetext{
${ }^{2}$ Following the literature, we consider investments to be for customization purposes with no intrinsic value outside the relationship. The interaction between a supplier and the firm is therefore not affected by imitation as we are dealing with a supply chain and inter-related technologies rather than a one-to-one buyer-supplier relationship.
} 
supply chain, making outsourcing a less meaningful tool to create investment incentives for suppliers located further downstream. The final producer therefore chooses to hold on to a larger share of revenues and integrates that stage. This tends to occur at the most downstream outsourced stages, making integration the outcome at an earlier (more upstream) stage of production. There are the stages that are most sensitive to IPRs in the supplier location. Strengthening the IPR regime puts the property right channel back in place, allowing the firm in control of the supply chain to exploit the advantages of outsourcing on supplier incentives to invest.

The results hint at a reduction in imitation-induced integration in the relatively downstream stages, expanding the range of inputs in the supply chain that are outsourced. This highlights the crucial role of IPRs for the organizational mode along "complementary" stages. However, we observe both theoretically and empirically that the protection of intangible assets tend to be a less relevant argument when stages are sequential substitutes. Conceptually, this is because the static and the dynamic effects of the organizational mode on supplier investments work against each other in the latter case. The dynamic negative effect of outsourcing on investment and revenues dominate when IPRs are strong (yielding the Antràs and Chor (2013) case), whereas they are reduced in magnitude under imitation and offset by the positive static effect. ${ }^{3}$

Our results obtain at the product level, and when aggregated to show the proportion of a firm's integrated inputs in each partner country. The findings remain robust to a series of checks that control for unobserved firm-specific effects and unobserved heterogeneity. The idea is further confirmed by showing that the regularity only holds for intangible assets as other institutional features relevant for contract enforcement such as the rule of law do not reproduce the effect of IPRs. We also complement the original measure of input complementarity/substitutability with a direct proxy for the degree of differentiation between inputs throughout the analysis and obtain a similar pattern for all cases.

The rest of the paper is organized as follows. Section 2 provides a brief background on our baseline theoretical framework that is essentially derived from Antràs and Chor (2013) and Alfaro et al. (2015). In Section 3 we introduce the presence of intangible assets and the possibility of imitation into the model. Section 4 introduces the data and provides a detailed description of the measures used in our specifications. In section 5 we directly test the predictions of our model and discuss the evidence obtained on the validity of our hypothesis on the relevance of intellectual assets in comparison with the underlying theory. Section 6 concludes and put forth avenues for further research.

\footnotetext{
${ }^{3}$ By static we intend the impact of outsourcing/integration on incentives for supplier investment in the same stage, and by dynamic on all the upcoming stages along the supply chain.
} 


\section{Theoretical Background}

For expositional convenience, we introduce the theoretical framework by considering, first, the baseline model, which basically corresponds to the model of Antràs and Chor (2013) in its simplest version. After having acquainted the reader with the mechanisms at work in this type of setting, we will then extend the model in Section 3, by introducing and modelling the risk of imitation and by illustrating how this innovation will affect the main theoretical results.

\subsection{The baseline model: key-assumptions}

We consider an economy in which the final good is available in many differentiated varieties, each one manufactured by a monopolistically competitive producer. Preferences are described by a standard CES utility function, thereby each producer (the firm) faces a demand for its variety given by

$$
q=A p^{-\frac{1}{1-\rho}}
$$

where $A>0$ is a demand shifter that the firm treats as exogenous; $p$ is the profit-maximizing price for the variety, set by the firm; and $\rho \in(0,1)$ is a measure of elasticity of the final demand, since it is positively related to $1 /(1-\rho)$, i.e. the degree of substitutability among varieties.

While the representation of demand side of the economy is stripped-down, the supply side features more complexity. In order for a unit of each variety to be produced, there is a continuum of stages of production that must be completed in a precise order, dictated by technology. Each stage is therefore indexed by $z \in[0,1]$, where $z=0$ is the first stage to be performed (the most upstream), whereas $z=1$ is the last one (the most downstream). To make the model easier, we consider the case in which all stages are symmetric except for their position along the production line.

At the end of each stage $z$, a (quality-adjusted) quantity of intermediate good $x(z)$ is delivered to the next stage of production for further reprocessing. Hence, at each stage of production, the intermediate input gets closer to the final good variety. A key-feature of the model is that, at any stage $z$, the intrinsic value of the variety can be increased by means of a stage-specific investment, with marginal cost $c>0$, which is intended to raise the level of customization of the intermediate good. ${ }^{4}$ It follows that the quality-adjusted volume of the final good production is a function of all the stage-specific investments in input services undertaken along the value chain, i.e.

$$
q=\theta\left(\int_{0}^{1} x(z)^{\alpha} I(z) d z\right)^{1 / \alpha}
$$

where $\theta$ is a productivity parameter, which reflects heterogeneity among firms; $\alpha \in(0,1)$ is the

\footnotetext{
${ }^{4}$ Both the firm and its suppliers are assumed to be capable of producing a non-customized input at a zero marginal cost, which allows for the continuation of the production process but does not add any value to final-good production.
} 
degree of physical input substitutability; and $I(z)$ is an indicator function which report us whether stage $z$ has been completed or not. This feature makes the production process inherently sequential, since downstream stages are useless unless inputs from upstream stages have been delivered.

We assume that, albeit in control of the whole production process, the firm is unable to complete any single stage of this process without cooperating with a dedicated supplier. Hence, for each stage $z$, there is a bundle of suppliers endowed with the skills or the know-how required for performing stage $z$ by customizing the product; we also assume that suppliers have a strong preference for staying into the relationship with the firm, their outside option being normalized to zero. As a result, at all stages of production, a supplier engages into a stage-specific contractual relationship with the firm for the procurement of a fully customized input $x(z)$, which is of worthless for alternative buyers. We can thus interpret $x(z)$ in equation (2) as a measure of the level of investment by supplier $z$.

The last ingredient to be added in the model is contract incompleteness. We assume that none of the aspects of input production can be disciplined by means of a comprehensive ex-ante contract, which obviously may give rise to a standard hold-up inefficiency in form of suppliers' underinvestment. In particular, we consider the case in which the initial contract specifies only whether the supplier appointed at stage $z$ will be integrated within the firm's boundaries or will remain independent as stand-alone entity. For further details about the key-assumptions of the model, please refer to the original work of Antràs and Chor (2013) or Alfaro et al. (2015).

\subsection{The baseline model: equilibrium}

The timing of the model is therefore the following. The firm posts contracts for suppliers for each stage $z \in[0,1]$, stating the organizational mode (integration or outsourcing), and then chooses for each $z$ one supplier among the applicants. Production then takes place sequentially. The supplier appointed for stage $z$ is handed the semi-finished good completed up to that stage in production, and is supposed to deliver its intermediate input to the immediate downstream supplier. Because of incomplete contracts, supplier $z$ is free to choose the volume of input services $x(z)$ that maximizes its profits, conditional on the value of the intermediate good that has been delivered to it.

This choice is based on two considerations. The first concerns the organizational mode chosen by the firm at stage $z$. Under vertical integration, the firm is in control of the physical assets used in the production of the intermediate input, which allows it to extract more surplus from the stage-specific investment in input customization. We model this aspect by assuming that, when the supplier is integrated within the firm boundaries, the firm appropriates of a large share of the value of supplier $z$ 's incremental contribution to the total revenue, this share being denoted by $\beta_{V} \in(0,1)$. At the opposite, under outsourcing strategy, the firm receives only a share $\beta_{O}<\beta_{V}$ of that surplus, while the rest accrues to the supplier. It stands to reason that, foreseeing a lower return to their investments, integrated suppliers will under-invest relatively more than stand-alone ones. 
The second determinant of the supplier investment decision is represented precisely by the value of its incremental contribution to the firm total revenue, i.e. by size of the surplus over which the supplier and the firm engage in a generalized Nash bargaining. ${ }^{5}$ This incremental contribution can be proved to be

$$
r^{\prime}(z)=\frac{\rho}{\alpha}\left(A^{1-\rho} \theta^{\rho}\right)^{\frac{\alpha}{\rho}} \cdot[r(z)]^{\frac{\rho-\alpha}{\rho}} \cdot[x(z)]^{\alpha},
$$

which is the derivative in $z$ of the revenue function valued at stage $z$, namely

$$
r(z)=A^{1-\rho} \theta^{\rho}\left(\int_{0}^{z} x(s)^{\alpha} d s\right)^{\frac{\rho}{\alpha}} .
$$

According to equation (3), the marginal contribution of supplier $z$ can be either increasing or decreasing in the revenue secured up to a stage $z$, i.e. in the amount of prior upstream investments, summarized in $r(z)$. Indeed, everything depends on the relative size of parameters $\rho$ (the final demand elasticity) and $\alpha$ (the degree of physical input complementarity). If $\rho>\alpha$, then higher investments by upstream suppliers increase the marginal return of supplier $z$ 's own investment. Following Antràs and Chor (2013) and Alfaro et al. (2015), we will refer to this case as the complements case, given that investment choices turn out to be sequential complements along the production line. At odds, if $\rho<\alpha$, higher investments by upstream suppliers reduce the marginal return of investment by supplier $z$; we will refer to this occurrence as the substitutes case, since investment decisions become sequential substitutes along the value chain. ${ }^{6}$

Hence, at the beginning of each stage $z$, the supplier is handed the intermediate product completed up to that stage and learns about the value of this product, i.e. $r(z)$ in equation (3). Based on this, and based on the share $\beta(z)=\left\{\beta_{O}, \beta_{V}\right\}$ chosen by the firm at stage $z$, the supplier determines its optimal input level, namely $x(z)$, solving the following problem:

$$
\max _{x(z)}(1-\beta(z)) r^{\prime}(z)-c x(z)
$$

The equilibrium of the game implied by the model can be solved by backward induction. Knowing the suppliers' optimal investment choice conditional on the organization mode, the firm can determine the pattern of ownership rights along the supply chain that maximizes its own profits. The firm's problem therefore consists of finding, for each $z \in[0,1]$, the optimal value of share $\beta(z)$ between $\beta_{O}$

\footnotetext{
${ }^{5}$ The actual payment to each supplier is negotiated bilaterally only after that the corresponding stage has been completed, and the terms of exchange are not renegotiated at a later stage. Moreover, this negotiation is treated as independent from bilateral negotiations that take place at other stages of production.

${ }^{6}$ Given $\alpha \in(0,1)$, supplier investments are always (weakly) complementary from a purely technological standpoint, which makes the complements case intuitively clear. However, under some circumstances, supplier investments (in quality-adjusted terms) may turn into sequential substitutes, as a result of a revenue effect large enough to dominate the physical input complementarity effect. This occurs for sufficiently low value of $\rho \in(0,1)($ the final demand elasticity), which makes the firm's revenue function highly concave in quality-adjusted output; large upstream investment levels therefore significantly reduce the value of undertaking downstream investments.
} 
and $\beta_{V}$, thereby determining whether the contract relative to any input $z$ will be associated with integration or outsourcing. In formal terms, the problem can be written as

$$
\max _{\beta(z) \in\left\{\beta_{O}, \beta_{V}\right\}} \pi=\Phi \int_{0}^{1} \beta(z)(1-\beta(z))^{\frac{\alpha}{1-\alpha}}\left[\int_{0}^{z}(1-\beta(s))^{\frac{\alpha}{1-\alpha}} d s\right]^{\frac{\rho-\alpha}{\alpha(1-\rho)}} d z
$$

where $\Phi$ is a constant term. We refer the reader to Antràs and Chor (2013) for a detailed derivation of the solution to this problem, which identifies the optimal organizational structures represented in Figure 1 . In the complements case $(\rho>\alpha)$, there exists a unique cut-off stage $z_{C}^{*} \in(0,1]$, such that all earlier stages are outsourced, and all later stages are integrated within firm boundaries. At the opposite, in the substitutes case $(\rho>\alpha)$, the unique cut-off is represented by a production stage $z_{S}^{*} \in(0,1]$ such that all upstream stages are retained within firm boundaries, whereas all stages located downstream are associated with outsourcing.

In Figure 2 we provide a graphical representation of the key-insight behind these patterns, by considering a relaxed version of the firm's problem, in which the optimal share $\beta(z)$ is not constrained to be either $\beta_{V}$ or $\beta_{O}$, but can take any real value (we only require $\beta(z)$ to be a piece-wise continuously differentiable real-valued function of $z$ ). As shown in the figure, in the complements case the optimal share $\beta^{*}(z)$ is an increasing function of $z$, which means that integration gets more appealing to the firm, the more production moves downstream. Since supplier investments are sequential complements, a virtuous cycle of investments may be triggered by incentivizing upstream investments by means of outsourcing. At a given stage of production, the marginal return to investments will be so high that suppliers will keep investing even if integrated, thus the firm will focus on the rentextraction motive for integration. This pattern is no longer consistent when suppliers investments are sequential substitutes, since large upstream investments (secured by arm's length arrangements) would dampen the incentives for downstream suppliers. The optimal pattern of ownership rights is then reversed, in compliance with $\beta^{*}(z)$ being a decreasing function of $z$.

Figure 1: Optimal pattern of ownership along the value chain (baseline model).

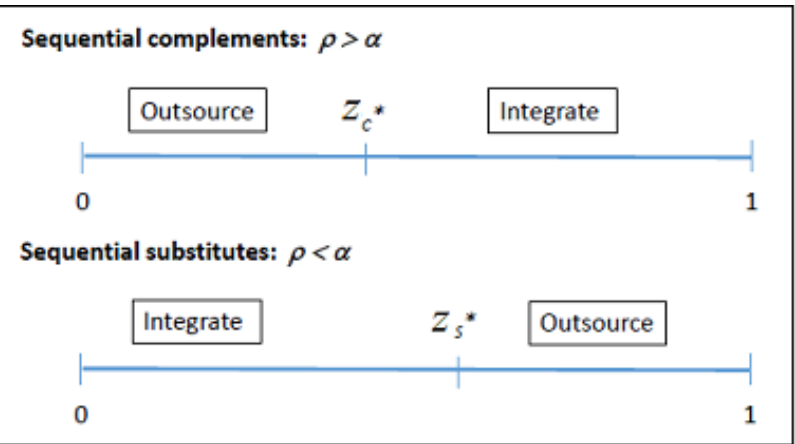

Source: Alfaro et al. (2015). 
Figure 2: Profit-maximizing division of surplus for stage $z$ (baseline model).

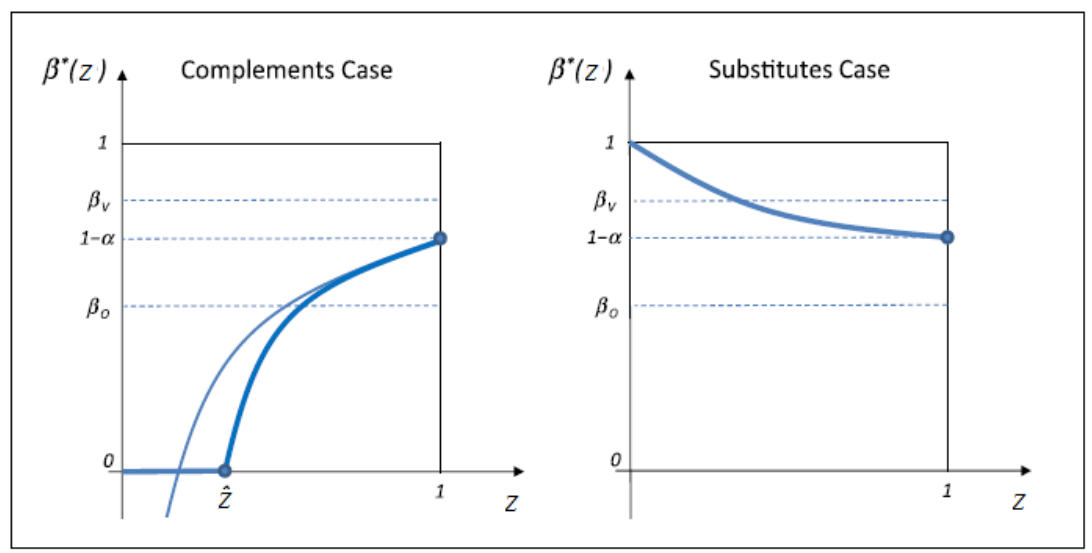

Source: Supplement to Antràs and Chor (2013).

\section{Non-appropriability of Intellectual Assets}

In this Section we propose an extension of the baseline model in which firms are exposed to the risk of their final-good variety being imitated by potential competitors, thereby highlighting how the optimal firm-boundary choices along the value chain might be affected by the degree of appropriability of intellectual assets. In so doing, we introduce a completely new element in the analysis, represented by the intangible dimension of production within modern supply chains and, consequently, by the role of intellectual property rights (IPR) protection.

\subsection{The generalized model: introducing the risk of imitation}

We consider a supply chain in which completing each stage of production with a fully customized input requires a two-way transfer of a different blueprint between the firm in control of the whole production process and the supplier appointed at that stage. Every blueprint contains (least part of) the relevant technology for developing that stage in production, or the know-how developed as a result of the investment in customization undertaken by the supplier. If the institutional environment in which production occurs were characterized by incomplete contracts but full IPR enforcement, the technology transfer would be smooth, safe and complete; the output of the final good $q$ would be realized with the accomplishment of stage $z=1$ and the total revenue from the sale of each variety would be collected by the corresponding firm. The organizational structure of the supply chain would therefore be the one described in Section 2.2 .

Consider now the case in which contract incompleteness combines together with the lack of full IPR protection. In this setting, a potential competitor of the final-good producers can come up with a copy of one of the varieties available in the market, and can start supplying this product without incurring in sanctions or penalties. Think of this competitor as an agent who is able to 
produce only a subpar version of the final good (of zero value for the market) since it misses the relevant technology for customizing the inputs and thereby creating its own differentiated variety. If intellectual property is not adequately protected, during the technology transfer among the firm and one of its suppliers, part of the content of the blueprint might somehow be diffused outside the relationship, in form of leaks or disclosure of relevant information or, more simply, of evidence about the intrinsic characteristics of the product. Based on this, a potential competitor can infer or acquire the know-how for reproducing the original production process, imitating the final good variety and thereby inflicting a dead-weight loss to the original producer (the firm) and all its suppliers. ${ }^{7}$

We assume that imitation is costless for the potential competitor and is independent of the firmboundary choices along the value chain, thereby excluding that one specific organizational mode might be used strategically by the firm to reduce the risk of its variety being imitated. In our model the economic value is indeed generated across production stages by overlapping investments in input customization, which stem from the fruitful cooperation between the firm and the suppliers, regardless of whether the latter are independent or not. Hence, even allowing for product imitation, we assume that the outside option of each supplier remains zero, on the ground that a stand-alone blueprint has no intrinsic value for the supplier outside the relationship with the firm.

A key-feature of our variant of Antràs and Chor (2013) is that we treat imitation as an exogenous shock that can occur at any stage of production, according to a standard Poisson process with arrival rate $\mu>0$. Intuitively, this rate is inversely related to the strength of IPR protection in the location in which production occurs (in addition to other intrinsic characteristics of the technology of production): the higher is the level of safeguard of intellectual property, the more $\mu$ approaches to zero, thereby restoring the baseline version of the model without imitation. Notice that the arrival rate of the shock is here assumed to be independent of the level of investment of each individual supplier and, more in general, to be homogeneous across stages. In principle, one could think of the blueprint transferred at given stage $z$ as more relevant for allowing imitation of the final product, as compared to the blueprint transferred at any other stage of the supply chain. However, modeling this aspect would entail specifying the location (upstream or downstream) of the "relevant" stage, i.e. a feature of the technology of production that might vary from one industry to another one. Assuming a constant $\mu$ across stages therefore appears as the most neutral assumption that can be put forth in order to capture the effect that we are mostly interested in.

Once the shock has arrived, i.e. imitation has occurred, none of the participants in the original value chain are willing to invest in the process any longer. Given the properties of the Poisson

\footnotetext{
${ }^{7}$ In this paper, we do not characterize the equilibrium in the final-good market in the presence of imitation, our interest being on the way according to which firms strategically modify the organizational structure of the supply chains to internalize their exposure to the risk of imitation. It suffices to say that imitation is always beneficial for the potential competitor, whatever is the division of the market with the original producer, whereas it is always detrimental for the firm and for all its suppliers, reducing their surplus necessarily due to the loss of exclusivity of the manufactured product.
} 
process, the expected value of supplier investments at stage $z$ is therefore

$$
e^{-\mu z} x(z)+\left(1-e^{-\mu z}\right) 0=e^{-\mu z} x(z)
$$

where $e^{-\mu z}$ is the probability that, up to the moment in which supplier $z$ enters the production line, imitation has not occurred and the whole production process is still in place.

Based on these assumptions, we can derive a particular statistical representation for the (qualityadjusted) value of production ex-ante, i.e. at the moment (corresponding to stage 0) at which the firm has to decide the optimal allocation of property rights along the value chain. This is a modified

version of equation (2), and precisely

$$
q=\theta\left(\int_{0}^{1}\left[e^{-\mu z} x(z)\right]^{\alpha} I(z) d z\right)^{1 / \alpha}
$$

Notice that, according to the above specification, the ex-ante value of the input services declines as far as we consider more downstream suppliers. It is important to stress that this is simply the result of their position along the supply chain, which increases the probability for their contribution to be zero, given that imitation will be more likely to have occurred by the time at which their contribution is required. Hence, the expected value of investments by downstream suppliers only depends on the engineering order of their participation to the supply chain, and not on their lower propensity to invest in input customization (conditional on imitation not having occurred).

The other elements of the model remain the same as in the baseline version, particularly the interaction between the supplier and the firm. Indeed, introducing non-appropriability of intellectual assets does not alter this type of interaction, as long as we deal with sequential production processes and inter-related technologies, rather than one-to-one buyer-supplier relationships.

\subsection{The generalized model: equilibrium}

We now characterize the optimal organizational structure of the supply chain for the case of our generalized version of the model. While we discuss here the main insights behind our results, Appendix A reports a more detailed derivation of the solution of the generalized firms' problem, where the latter corresponds to the following program:

$$
\max _{\beta(z) \in\left\{\beta_{O}, \beta_{V}\right\}} \pi=\Phi \int_{0}^{1} \beta(z)\left[e^{-\mu z}(1-\beta(z))\right]^{\frac{\alpha}{1-\alpha}}\left[\int_{0}^{z}\left[e^{-\mu s}(1-\beta(s))\right]^{\frac{\alpha}{1-\alpha}} d s\right]^{\frac{\rho-\alpha}{\alpha(1-\rho)}} d z
$$

Consider Figure 3, which is the counterpart of Figure 2 for the extended model with risk of imitation. The function $\beta^{*}(z)$ reported in the figure is then the solution to a relaxed version of program (6), in which the optimal share $\beta(z)$ is not necessarily chosen in the pair of values $\beta_{O}$ and $\beta_{V}$, but can take any value in the interval $[0,1]$. In analogy with the baseline model, $\beta^{*}(z)$ is an increasing function 
of $z$ in the complements case $(\rho>\alpha)$, while it is a decreasing function of $z$ in the substitutes case $(\rho<\alpha)$. The two patterns identified in Section 2.2 are therefore still valid: even under risk of imitation, the firm will outsource upstream and integrate downstream in the first case; and will integrate upstream and outsource downstream in the second. ${ }^{8}$

Figure 3: Profit-maximizing division of surplus for stage $z$ (generalized model).

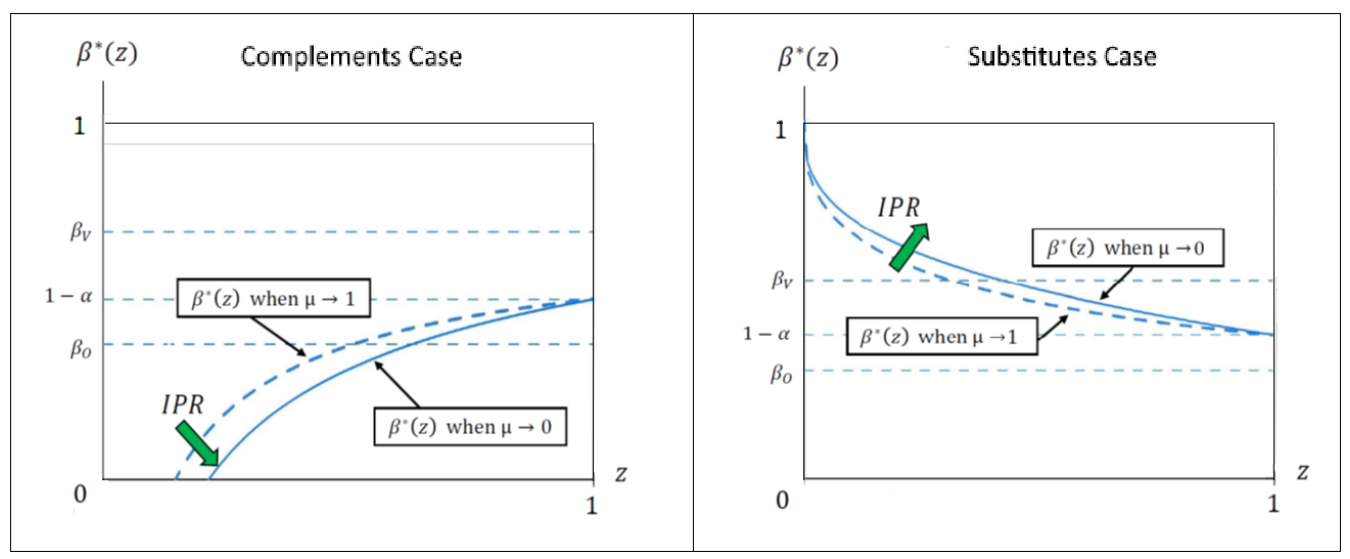

However, Figure 3 reveals a crucial aspect which differentiates the case of non-appropriable intellectual assets (low IPR protection, i.e. $\mu>0$ ) with respect to the baseline model (where $\mu=0$, because of full IPR protection). In the complements case, at any stage $z$ the optimal value of $\beta(z)$ is indeed higher in case of non-appropriable intellectual assets (dashed line) than in the case with full appropriability (solid line); thus, the non-appropriability of intellectual assets increases the overall appeal of the integration strategy along the supply chain. At odds, in the substitutes case, a weak IPR regime tends to decrease the incidence of integration; for any $z \in[0,1]$, the optimal value of $\beta(z)$ is indeed lower in the event of $\mu>0$ (dashed line) than in the baseline model, where $\mu=0$ (solid line). Based on this, we can derive the following predictions, illustrated in Figure 4.

Proposition 1 In the complements case $(\rho>\alpha)$, the cut-off stage $z_{C}^{*} \in(0,1]$, such that all upstream stages are outsourced, and all downstream stages are integrated, is decreasing in $\mu$, and therefore increasing in the level of appropriability of intellectual assets (i.e. the strength of IPR protection in the location in which production occurs).

Proposition 2 In the substitutes case $(\rho<\alpha)$, the cut-off stage $z_{S}^{*} \in(0,1]$, such that all upstream stages are integrated, and all downstream stages are outsourced, is increasing in $\mu$, and therefore decreasing in the level of appropriability of intellectual assets (i.e. the strength of IPR protection in the location of production).

\footnotetext{
${ }^{8}$ As in Antràs and Helpman $(2004,2008)$, the solution to the relaxed problem is used to establish whether the firm will choose outsourcing or integration at the very beginning of the supply chain, selecting the higher $\left(\beta_{V}\right)$ or the lower $\left(\beta_{O}\right)$ value of $\beta(z)$ at $z=0$. As regard to the baseline model, Antràs and Chor (2013) provide a clear treatment of the conditions under which (i) integration and outsourcing coexist along the value chain and (ii) the set of stages under a common organizational form (integration or outsourcing) is a connected interval in $[0,1]$. The same conditions apply to the our variant of the model (see Appendices A-2, A-3 and A-4).
} 
Figure 4: Optimal pattern of ownership along the value chain (baseline model).

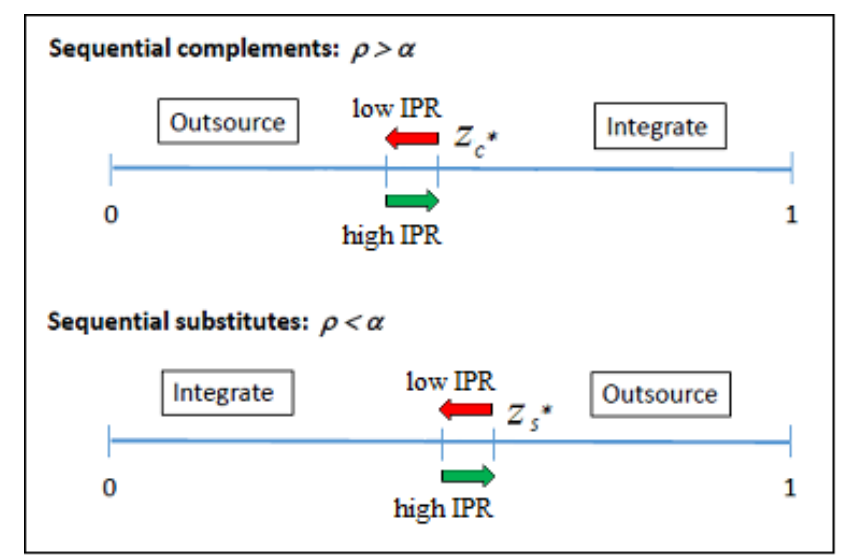

We can rationalize Proposition 1 as follows. When supplier investments are sequential complements, the preferred option at the beginning of the chain is outsourcing, to secure a large amount of upstream investments that will raise incentives for downstream suppliers. Under risk of imitation, the positive dynamic effect of upstream investment is increasingly offset along the supply chain by a higher probability of disruption of the production process. This induces firms to focus on rent extraction therefore increasing its propensity to integrate as production moves downstream. The firm will therefore anticipate the stage at which integration occurs. Enforcing IPRs (i.e. lower $\mu$ ) tends to restore the original cut-off that characterizes the baseline version of the model, extending the range of stages that are outsourced.

A similar argument can be used also for Proposition 2. In the substitutes case, upstream stages are associated with integration, thereby avoiding the negative effect on incentives for downstream suppliers that would be generated by outsourcing and therefore by large upstream investments. Under imitation, a lower probability of survival works against the negative dynamic effect that outsourcing exerts on investment at more downstream stages. One can think of such uncertainty bringing forward the final stage of production in view of the firm, rendering a larger pie at any given stage through outsourcing more attractive. The negative effect of outsourcing on investment at future stages is mitigated as the production process is less likely to reach the next stage. As a result, outsourcing becomes more appealing as a strategy at relatively earlier stages of production, as compared to the baseline model. Also in this case, enforcing IPR has the effect to restore the original cut-off even though, in this case, by reducing the range of stages that are outsourced. ${ }^{9}$

The last theoretical prediction of the model regards the heterogeneous impact of IPR protection in the case of complements and substitutes. In Appendix A-5 we show that, for a given absolute difference of parameters $\alpha$ and $\rho$, the derivative of $\beta^{*}(z)$ with respect to $\mu$ is larger when the difference is negative $(\alpha<\rho)$ rather than positive $(\alpha>\rho)$. This means that a change in level of IPR

\footnotetext{
${ }^{9}$ Both the cut-off stages $z_{C}^{*}$ and $z_{S}^{*}$ are derived in a closed-form solution in Appendix A-4.
} 
protection has a larger (lower) effect on the optimal share of ownership at any stage of production, as far as supplier investments are sequential complements (substitutes) along the value chain. We can therefore establish Proposition 3.

Proposition 3 Ceteris paribus, the choice of the organizational mode at each stage of production is more sensitive to the degree of appropriability of intellectual assets (the strength of IPR protection) in the complements case $(\rho>\alpha)$, rather than in the substitutes case $(\rho<\alpha)$.

The intuition behind this result can be illustrated by noticing that a given organization mode, say outsourcing, always exerts two types of effects. One is the "dynamic" effect, i.e. the effect on the incentives for all downstream suppliers, that can be either positive or negative (for outsourcing) depending on whether supplier investments are, respectively, complements or substitutes along the supply chain. The second effect is the "static" effect, which refers to the level of supplier investment at the stage in which this organization mode occurs. In the case of outsourcing, this effect is always positive: ceteris paribus, an integrated supplier will underinvest as compared to a stand-alone supplier, regardless of the nature of suppliers investments (complements or substitutes). Under full IPR protection, the dynamic effect is paramount and drives the allocation of property rights across all stages of production, making the "static" effect of each organization mode of limited relevance to this purpose. Under a weak IPR regime, instead, the dynamic effect becomes less relevant as the firm discounts what occurs at the next stages of production by the lower probability that production will still be in place (more and more blueprints are transferred as production moves downstream). We can therefore detect an evident asymmetry between the case of complements and substitutes. In the complements case, the dynamic effect of outsourcing is positive at any stage of production but gets weaker, the weaker is the level of enforcement of IPRs; however, the decision to outsource at a given stage $z$ will always be supported by the positive static effect associated with this particular organization mode. On the contrary, in the substitutes case the dynamic effect of outsourcing is negative for all $z$; with the lack of IPR protection, this effect gets weaker and finds stronger opposition by the static effect, which is positive. Integration and outsourcing are therefore more interchangeable among each other at all stages of the supply chain, which explains why enforcing or not enforcing IPRs has a weaker impact on organization in this second case.

\subsection{From theory to empirics: testable predictions}

It follows from the model that IPRs bear important implications for firm decision on the organization mode at different (sequential) production stages and different degrees of sequential complementarity of its inputs/stages. For any given location, a firm decides to integrate or outsource stage $z$ based on the characteristics of its inputs. However, we observed that technology and final demand-side factors (e.g. $\alpha, \rho$, upstreamness) cannot entirely explain the outsourcing/integration decision across different 
markets and production stages. Our argument is that this is due to the existence of intangible assets along the value chain. The theory therefore focuses on the role of IPR protection as one of the crucial market-specific characteristics behind the firms' decision on organization of their global value chains when assets are not fully appropriable.

Based on the propositions of the theoretical model we derive predictions to be tested empirically on the firm-level data about the effects of IPR enforcement on firms' outsourcing versus integration decision along their sequential supply chains. As shown by the model, the strength of IPR protection in the location of production of an input affects the incidence of internalization, and the impact depends on the position of the stage along the value chain and varies systematically between sequential complements and substitutes.

We formulate three principal testable predictions as follows:

Prediction 1. When inputs are sequential complements, imitation risk increases likelihood of integration of the firm; within a firm, this occurs for the more downstream stages not yet integrated.

Recall that in the case of sequential complements, downstream stages are already integrated. Prediction 1 suggests that among the stages not yet integrated, those that lie more downstream on the value chain are most sensitive to IPR protection. Hence, it is in those relatively downstream stages, where we expect to observe reduced incentives to integrate as a result of stronger IPR protection.

Prediction 2. When inputs are sequential substitutes, imitation risk increases likelihood of outsourcing of the firm; within a firm, this occurs for the more downstream stages not yet outsourced.

Recall that in the case of sequential substitutes, downstream stages are already outsourced. Prediction 2 suggests that among the stages not yet outsourced, those that lie more downstream on the value chain are most sensitive to IPR protection. Hence, it is in those relatively downstream stages, where we expect to observe increased incentives to integrate as a result of stronger IPR protection.

Prediction 3. IPR enforcement is more relevant for the organizational decision when inputs are sequential complements.

Proposition 3 suggested that the impact of imitation on supply chains with inputs that are sequential substitutes are weaker than those with sequential complements. Prediction 3 derives from this result, implying reduced relevance of the choice of the organizational mode under sequential substitutes when a firm faces imitation. Intangible assets and IPRs should therefore not have a significant effect on the integration decision of firms in supply chains with such characteristics.

To test the above predictions, ideally one would need firm level data on the entire set of inputs sourced from different countries along the entire supply chain together with information whether the 
inputs are provided internally within the firm or procured from non-related firms. Since such a rich and detailed database on the level of firms' trade transactions further disaggregated into intra-firm and arm's lengths type is not readily available, at least for a wider spectrum of industries and firms, our approach exploits the availability of matched firm-level transaction trade data and firms' bilateral foreign direct investment flows. Apart from the firm decision on outsourcing versus integration of different inputs in different markets, empirical testing of the model's predictions requires the identification of the position of a particular input in the value chain, i.e., upstreamness, and distinction between sequential complements and substitutes cases. The approach we follow in the construction of our core variables and data sources are described below.

\section{Data and Key Variables}

The dataset we use consists of four distinct databases covering the population of Slovenian firms in the 2007-2010 period. Our core database includes transaction-level trade data at the 8-digit level of European Combined Nomenclature (hereinafter CN) classification provided by Statistical Office of the Republic of Slovenia (SURS). This is merged by the unique firm identifiers with (i) detailed information on direction of firms' cross-border direct investment outflows provided by Bank of Slovenia and (ii) with firms' financial statements data from the Agency for Public Legal Records and Related Services (hereinafter APLR). Hence, we have on disposal firms' annual export and import transactions to/from partner countries as well as their outward FDI positions in respective host partner countries. Additionally, we use a database on the performance of the affiliates of Slovenian firms located abroad provided by Bank of Slovenia, which contains further information on affiliates performance, core industry of activity and trade flows, e.g. total exports and imports of affiliates, their total intra-firm trade and sales in the local (host) market.

Slovenia is a highly open, small economy from the group of CEE transition economies that since the mid-1990s has been heavily involved in both multilateral liberalization and regional integration processes mostly related to approaching EU membership: (i) accession to the GATT (WTO) in 1994 (1995); (ii) CEFTA membership in 1996; (iii) signing of an Association Agreement with the EU in 1996 and provisionally enforced in 1997; and (iv) EU accession negotiations between 1998-2002. In year 2004 Slovenia became a full member of the EU and adopted, as the first new EU member state, Euro in 2007. Liberalization processes contributed to increasing involvement of Slovenian companies in global value chains (hereafter GVC). According to the WTO Slovenia is classified among the high(GVC) participation economies and recorded a GVC participation index of 58.7 in 2011 which is significantly above the average value for developed and developing countries, i.e. 48.6 and 48.0, respectively, mostly on account of strong backward participation (WTO, 2016) as shown in Table B1 of the Appendix. Figures B1 and B2 in the Appendix also show the value-added components of 
gross exports for Slovenia in 1995 and in 2011, together with the comparison between inward and outward FDI. It is clear from the figure that outward FDI dominates for Slovenia and that the gap between inward and outward FDI has been expanding over the last decade.

These developments support our belief that the comprehensive database of Slovenian firms offers a suitable setting for studying firm organization behavior along international value chains. In our final sample, we have 6010 firms that record imports from 171 and/or outward FDI with 37 different partner countries.

\subsection{Dependent variable - binary variable on the decision to integrate}

We aim to measure the decision to integrate or outsource inputs in different countries at different stages of the value chain. In so doing, we combine trade and FDI flow firm-level data to estimate the propensity of a firm to integrate an input supplier. For the purpose of our analysis, we define products (inputs) as the 6-digit level product groups of $\mathrm{CN}$ classification that is in full compliance with the 6-digit Harmonized system (hereinafter HS) code. Transaction trade data provides us with information on the complete set of inputs sourced from abroad at the firm-level, while FDI data gives the location of the dependent establishments. We, however, do not have information on the extent to which trade flows are carried out within the firm (intra-firm trade). Earlier studies have faced the issue by exploiting available industry-level intra-firm trade data and using the share of intrafirm imports in total inputs as an indication of the propensity to transact a particular input within firm boundaries, e.g. Antràs and Chor (2013). Follow-up studies instead define the integration vs outsourcing decision based on the (core) activities of establishments linked via ownership ties (net of subsidiaries of the "global ultimate owner"), e.g. in Alfaro et al. (2015). While the former approach lacks information on the identity (activity) of the individual buyer, the latter does not use trade data and therefore uses Input-Output tables to determine the set of outsourced inputs without information on their location, which is in the focus of this paper.

We distinguish between integration and outsourcing by exploiting information on the core activity of the firm's affiliate in a particular host country in the manner adopted in Alfaro et al. (2015). We regard those inputs sourced by the parent firm from its affiliate's host country that are classified under the core activity of the affiliate as integrated inputs. More specifically, inputs a firm imports from its affiliate's host country that are classified under the core activity of the affiliate at the 4-digit industry level are regarded as integrated, whereas all other imported inputs from this country are considered as being outsourced. Doing this therefore accounts for the fact that a firm may engage in both integration and outsourcing in a partner country. In case a firm has no FDI in a partner country, all imports coming from that country are regarded as being outsourced. Such formulation allow us to estimate the regression model at the most disaggregated firm-market-product level. The dependent variable is defined as a firm's binary decision on whether or not to integrate a particular 
input supplier in a certain market, i.e. the propensity to transact an input in a particular source country within firm boundary. Moreover, it allows us to consider firm-input specific upstreamness measure for all bilateral firm transactions. We link the core activity of an affiliate and imported inputs by the parent company by first adopting Ramon's concordance from 6-digit HS 2002 to 6-digit CPA 2002 classification, and subsequently from CPA 2002 to NACE Rev. 1 at the 4-digit level based on the direct linkage in the structure of these two classifications. ${ }^{10}$ In year 2007, the HS classification underwent a substantial revision, therefore a pairing of HS6 2007 to HS6 2002 codes was required for the purpose of the linking core activity of an affiliate and imported inputs. In converting HS 2007 to HS 2002 codes we lean on the Van Beveren et al. (2012) concordance approach, but assign one single code of an HS 2002 edition to each HS 2007 code. This requires certain simplifications in the event that the HS 2007 code is the result of either merging (1:n relationship) or splitting and merging ( $n: n$ relationship) of several codes in the previous 2002 classification. In this case, we follow the United Nations Statistics Division (2009) and give priority to the one subheading among several that has the same code as the HS 2007 subheading (if it exists). The retained code rule is based on the general WCO praxis to maintain the existing code only if there has been no substantial changes of its scope.

\subsection{Complementarity/substitutability}

To distinguish between sequential substitutes and complements we follow Antràs and Chor (2013) and Alfaro et al. (2015) and trace substitutes/complements based on low/high value of import demand elasticities faced by the buyers of a particular good. We consider import demand elasticity of a firm's core export product, i.e. the product at 6-digit level of HS classification which accounts for the largest share in exports of a particular firm. As stressed by Antràs and Chor (2013), this approach implies the assumption that any existing cross-industry variation in elasticity of technological substitution across firms' inputs is largely uncorrelated with the elasticity of demand. Complements $\left(d \_c o m p l=1\right)$ are characterized by above-median import demand elasticity for a firm's core export product and substitutes $\left(d_{-}\right.$compl $\left.=0\right)$ by below-median demand elasticity. We use import demand elasticities estimated at 6-digit level HS product level for Slovenia by Kee, Nicita and Olarreaga (2008) following the production-based GDP function approach. Their estimated import demand elasticities are defined as the percentage change in the quantity of an imported good when the price of this good increases by $1 \%$, holding prices of all other goods, productivity, and endowments of the economy constant.

We complement this standard measure of distinguishing between sequential complements and substitutes in several ways. First, we propose an original proxy for $\alpha$, based on the premise that degree of physical input substitutability is closely related to the degree of input differentiation.

${ }^{10} \mathrm{CPA}$ classification is a product classification whose elements are for the goods part based on the HS classification. 
We assume that inputs classified within the same industry at certain digit-level of classification exhibit higher technological substitutability compared to inputs classified in different industries at the particular level of aggregation. To reflect substitutability among inputs in this regard we compute a Herfindahl index $\left(H_{i t}\right)$, which measures how (6-digit) imported inputs by a firm are spread across different (3-digit) industries. Our $H_{i t}$ counts 3 -digit imported product groups and weights them by the abundance of 6-digit product categories within each 3-digit group:

$$
H_{i t}=1-\sum_{n=1}^{N_{3 d i g}}\left(\frac{\#(6 \text { digit } H S)_{n}}{N}\right)^{2}
$$

where $n$ denotes product category at a 3 -digit level of HS, $N_{3 d i g}$ represents number of 3-digit product categories of HS, and $N$ the total number of imported products at 6-digit level of HS. When all imported inputs are classified under the same 3-digit industry, i.e. in case of high degree of input substitutability, $H$ is equal to 0 , whereas in case each input is classified under a different 3-digit category, $H=(N-1) / N$. In the next stage, we compute average values of the Herfindahl index $H_{i t}$ across 3 -digit industries to obtain industry-specific (inverse) alpha measure $\bar{H}_{j t}$.

Our first alternative approach of distinguishing between sequential substitutes and complements rests on below and above median value of the industry-level Herfindahl index, $\bar{H}_{j t}$ : in case a firm is classified in an industry with a below average value of $\bar{H}_{j t}$, i.e. relatively high substitutability among inputs, $d_{-}$complalpha_ind $=0$ representing substitutes, while for an above average value of the index $\bar{H}_{j t}, d_{-} c_{c o m p l} l_{\text {alpha_ind }}=1$ denoting sequential complements. This definition still implies the assumption of independence between $\rho$ and $\alpha$.

Therefore, we proceed with our second alternative for sequential substitutes/complements identification by considering both $\rho$ (import demand elasticity) and $\bar{H}_{j t}$ (industry-level Herfindahl index) to determine sequential complements/substitutes. More specifically, we take the product of import demand elasticity in absolute terms and $\bar{H}_{j t}$, and define a dummy variable $d_{-}$compl $l_{\text {rho_alpha_ind }}$ based on below and above median values of this product. The higher the import demand elasticity in absolute terms $(\rho)$ and higher the Herfindahl index (inverse $\alpha$ ), i.e. the lower the technological substitutability, more likely that $\rho>\alpha$, hence complements.

Since the Herfindahl index based approach to measuring $\alpha$ comes with certain limitations, in our third attempt to separate sequential substitutes/complements we modify the Alfaro et al. (2015) approach starting from the premise that $\alpha$ is closely related to the elasticity of demand for each intermediate input by firms in a certain industry. Following this, we define $\alpha$ as the weighted average of demand elasticities of the intermediate and capital good imports by a firm where a firm's import shares are used for weighting. We then take the difference between $\rho$ and this $\alpha$ measure and define complements when the difference is greater than $0\left(d_{-} c o m p l_{\text {rho_alpha_elast }}=1\right)$, and substitutes when it is below $0\left(d_{-}\right.$compl $\left.l_{\text {rho_alpha_elast }}=0\right)$. 


\subsection{Upstreamness/downstreamness}

Since we observe import transactions at the firm-level, we are able to identify the position of imported inputs in the value chain of a concrete firm's output, which we define by its core export product at 6 -digit level of the HS classification. Hence our upstreamness measure, namley $U_{p s t r}{ }_{i j t}$, is industrypair specific in the same manner as Alfaro et al. (2015) and following Fally (2012) and Antràs et al. (2012), and is expressed as the "average" distance of each input $h$ from the final demand in product $k$, for each pair $h, k$.

Following Alfaro et al. (2015), upstreamness of an input $h$ in the production of output $k$ is a weighted average of the number of stages it takes for $h$ to enter in $k$ 's production measured as:

$$
U p s t r_{h k}=\frac{d_{h k}+2 \sum_{m=1}^{M} d_{h m} d_{m k}+3 \sum_{m=1}^{M} \sum_{n=1}^{M} d_{h m} d_{m n} d_{n k}+\ldots}{d_{h k}+\sum_{m=1}^{M} d_{h m} d_{m k}+\sum_{m=1}^{M} \sum_{n=1}^{M} d_{h m} d_{m n} d_{n k}+\ldots},
$$

where $d_{h k}$ denotes direct requirement coefficient of input $h$ in output $k$ (where $h, k=1, \ldots, M$ ). The denominator is an infinite sum over the value of $h$ 's use that enters exactly $l$ stages removed from the production of $k$, while the numerator is similarly an infinite sum, but there each term is multiplied by an integer (the number of stages upstream at which the input value enters the production process). A larger $U_{p s t r}$, that is greater than 1 by construction, means that a greater share of the total input use value of $h$ is accrued further upstream in the production process for $k$. We use 2002 US Input-Output table provided by Industry Benchmark Division (IBD) of Bureau of Economic Analysis since the detailed input-output table for Slovenia is not available. U.S. SIC/NAICS product classes and industries from US Direct Requirements matrix are matched to HS codes of firms' core export product and imported inputs based on concordance provided by Pierce and Schott (2009) (available at: http://www.nber.org/data-appendix/w15548/readme.txt).

\subsection{Descriptive statistics}

Some of the key descriptive statistics of the analyzed variables are reported in Table 1, where we distinguish between sequential substitutes and complements based onbased on $r h o\left(d_{\text {compl }}\right)$.

Around 18\% of import transactions are carried out by firms with outward FDI in at least one year throughout the 2007-2010 period, and 3\% transaction by firms with outward FDI in a particular sourcing country in a given year where the share is slightly higher for sequential complements. However, less than $0.1 \%$ of import transactions are classified as integrated when condition of being classified under the core activity of the affiliate at the 4-digit industry level is applied. There are no notable differences observed between sequential complements and substitutes with respect to average upstreamness of their inputs, the sourcing countries effectiveness of IPR protection and rule of law implementation. They are as well similar, on average, in terms of their age, export propensity and financial leverage. However, compared to sequential substitutes, firms with their core export product 
characterized by complementarity of the suppliers investments along the value chain are on average smaller in terms of number of employees with lower average capital intensity of their production.

Table 1: Descriptive statistics

\begin{tabular}{lcccc}
\hline & \multicolumn{2}{c}{$\begin{array}{c}\text { Substitutes } \\
\left(\mathrm{d} \_c o m p l=0\right)\end{array}$} & \multicolumn{2}{c}{$\begin{array}{c}\text { Complements } \\
\left(\mathrm{d} \_c o m p l=1\right)\end{array}$} \\
\cline { 2 - 5 } & Mean & Std.Dev. & Mean & Std.Dev \\
\hline \multirow{2}{*}{ d_OutFDI } & 0.1792 & 0.383 & 0.1876 & 0.390 \\
d_OutFDI_bilateral & 0.028 & 0.166 & 0.032 & 0.177 \\
d integr_4dig & 0.0004 & 0.019 & 0.0003 & 0.018 \\
Upstreamness & 2.530 & 1.073 & 2.511 & 1.071 \\
IPR index & 4.521 & 0.252 & 4.519 & 0.2428 \\
Rule of law index & 1.297 & 0.647 & 1.296 & 0.650 \\
IM demand elasticity (abs) & 0.872 & 0.193 & 1.550 & 3.564 \\
Inputs demand elasticity (abs) & 1.118 & 1.019 & 1.190 & 0.738 \\
Age & 14.347 & 7.436 & 14.189 & 7.522 \\
Employment & 64.635 & 378.537 & 52.311 & 176.570 \\
Ex-Propensity & 0.306 & 0.320 & 0.294 & 0.322 \\
K-intensity & 96,659 & 642,423 & 83,036 & 292,799 \\
Debt assets ratio & 0.647 & 0.280 & 0.653 & 0.375 \\
\hline & \multicolumn{3}{c}{$460,757)$} & \\
No of observations & \multicolumn{3}{c}{348,392} \\
\hline
\end{tabular}

Note: Capital intensity (K-intensity) is expressed in EUR.

\section{Empirical Specifications and Results}

\subsection{Empirical model specifications and methodological issues}

\subsubsection{Empirical specifications}

The firm's decision to integrate suppliers in a certain market, i.e. its propensity to transact an input in a particular source country within firm boundary, is defined on the firm-market-product level based on the core activity of the affiliates in the spirit of Alfaro et al. (2015). The binary dependent variable of integration of a particular input from a particular country in a given year by a firm $\left(d_{-}\right.$integr $\left._{i h j t}\right)$ is based on requirement that an input a firm imports from a particular country is classified under the core activity of its eventual affiliate located in that country at the 4-digit industry level in a given year. We base our empirical model specifications on the Antràs and Chor (2013) model, and following our model's predictions augment it with the level of the IPR protection in a sourcing country.

In addition to the direct impact of IPR on integration of input suppliers in a certain market, the model predicts that IPR affects internalization decision also indirectly through influencing the interaction between input substitutability (complements/substitutes) and upstreamness. Since we have input-specific measure of upstreamness for each firm in each market, we can test these predictions by augmenting Antràs and Chor (2013) empirical model with the level of sourcing countries' IPR 
protection and its three-way interaction with $U p s t r$ and $d_{-} c o m p l$ variables:

$$
\begin{aligned}
& \operatorname{Pr}\left(d_{-} i n t e g r_{i h j t}=1\right)=\beta_{0}+\beta_{1} U_{p s t r}{ }_{h k}+\beta_{2} d_{-} c o m p l_{i t}+\beta_{3} I P R_{j t}+\beta_{4} U p s t r_{h k} * d_{-}{ }_{\text {compl }}+
\end{aligned}
$$

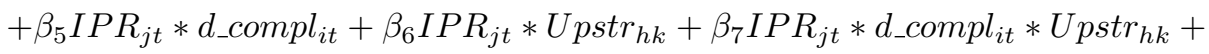

$$
\begin{aligned}
& +X_{i t}^{\prime} \beta_{8}+\sum \beta_{9, j} d_{-} \text {industry } y_{k}+\sum \beta_{10, t} d_{-} \text {country }_{j}+\sum \beta_{11, t} d_{-} \text {year }_{t}+u_{i h j t},
\end{aligned}
$$

where subscripts $i, h, k, j$ and $t$ refer to firms, inputs, (core) outputs, countries and years, respectively. The level of IPR protection $\left(I P R_{j t}\right)$ is measured as logarithm value of the Park index. Besides the complementarity and upstreamness variables, explained in the previous section, in the model specification we include vector $X_{i t}$ of standard, firm-specific controls: firm's age, size, capital intensity of production, labor productivity, export orientation and financial leverage. In particular, the size of a firm $\left(\right.$ size $\left._{i t}\right)$ is measured by the number of employees. The variable age ${ }_{i t}$ denotes a firm's age counting from the formation year according to the Business Register of the Republic of Slovenia. Further, we include capital-intensity (K_intensity ${ }_{i t}$ ), measured by fixed assets per worker, which according to the Olley and Pakes (1996) model affects the distribution of future plant productivity and may act as a proxy for unobserved sources of efficiency. Productivity is measured in terms of labor productivity, defined by value added per employee (L_productivity $\left.y_{i t}\right)$. Export orientation is defined as the share of exports in total sales of a firm (Ex_Propensity $\left.y_{i t}\right)$ and financial leverage as debt to assets ratio (Debt_assets $\left.s_{i t}\right)$.

We also include sets of (i) annual dummy variables to control for macroeconomic shocks, (ii) partner country dummies to take account for country-specific time-invariant effects, and (iii) industryspecific effects, where we define a firm's industry participation based on its core export product at 1-digit level of Harmonised System classification.

However, to observe and compare the heterogeneous impact of IPRs at different stages of the supply chain for the two cases of sequential complements and substitutes in a more direct manner, our preferred specification separates the sample into sequential complements and substitutes based on our alternative definitions of $\rho$ and $\alpha$. Split-sample specifications allow us to reduce the complexity of triple interaction to one interaction term between IPR and the upstreamness measure. For the sample split between sequential complements and substitutes, the specification turns to

$$
\begin{aligned}
& \operatorname{Pr}\left(d \_i n t e g r_{i h j t}=1\right)=\beta_{0}+\beta_{1} \text { Upstr }_{h k}+\beta_{2} I P R_{j t}+\beta_{3} I P R_{j t} * U_{p s t r}{ }_{h k}+ \\
& +X_{i t}^{\prime} \beta_{4}+\sum \beta_{5, j} d_{\_} \text {industry } y_{k}+\sum \beta_{6, t} d_{-} \text {country }_{j}+\sum \beta_{7, t} d_{-} \text {year }{ }_{t}+u_{i h j t} \text {. }
\end{aligned}
$$

\subsubsection{Methodological issues}

We use probit specification of our integration decision model (9-10). There are certain potential econometric concerns of estimating probit models that need discussion. In line with heterogeneous 
firm dynamics models the variability of firm growth usually decreases with firm size, suggesting that variance is not constant across firms. This might as well hold for firm integration decision. Therefore, we first test if firm size affects the conditional variance of the firms integration decision to detect potential heteroscedasticity. When Wald's test for heteroscedasticity rejects the null hypothesis of homoscedastic variance (i.e. $H_{0}: \ln \left(\sigma_{i}^{2}\right)=0$ ) we apply a maximum-likelihood heteroscedastic probit model that generalizes probit model by allowing the scale of the inverse link function to vary from observation to observation as a function of the independent variables (a firm size). Secondly, to deal with endogeneity which is caused by unobserved firm-specific effects we employ parameterization of unobserved firm-specific effects by firm-level means of all time-varying independent variables over the sample period, in the manner suggested by Mundlak (1978), Chamberlain (1984) and Wooldridge (2002). Additionally, we estimate random effects probit model and explicitly exploit panel structure of our data where unit of observation refers to firm-country-product level. Since we cannot control for these effects in the pooled probit model, this panel approach allows controlling for everything that remains constant during the sample interval with a partner country-product pair, i.e. firmcountry-product fixed effect. In the random effects model, firm-country-product specific effects are assumed a random variable that is uncorrelated with the explanatory variables.

\subsection{Core results}

We start with the results of specifications based on import demand price elasticities ( $\rho$ measure) and later on continue with the alternative specifications based on $\alpha$ measures. Table 2 depicts the results for the pooled sample with triple interaction, while Table 3 reports the split-sample results where sequential complements and substitutes are separated based on import demand price elasticities $(\rho)$. Column (1) in Table 2 and columns (1)-(2) of Table 3 show the results of probit model with the robust standard errors adjusted for firm clusters. When Wald's test rejects the null hypothesis of homoscedastic variance, the heteroscedastic probit model results are reported instead. Further, column (2) of Table 2 and columns (3)-(4) in Table 3 refer to specifications that, following Mundlak (1978), Chamberlain (1984), and Wooldridge (2002), include firm-level means of all timevarying independent variables over the sample period to control for unobserved firm-specific effects. Columns (3) and (5)-(6) in Tables 2 and 3, respectively, instead report the results estimated by random effects probit model where unobserved heterogeneities for each firm-country-product pair that are invariant over time are controlled for.

The results based on the aggregate sample presented in Table 2 confirm significant differences in the impact of IPR and upstreamness position on incidence of firm vertical integration of the inputs between sequential complements and substitutes as indicated by the significant interaction terms between dummy variable for the complements (d_compl) on one hand and IPR $(\ln I P R)$, upstreamness position (Upstr) and $\operatorname{lnIPR} *$ Upstr interaction on the other. The interaction of IPRs with 
complementarity is negative and highly significant suggesting that improvement in IPR protection on average encourages outsourcing when inputs are sequential complements compared to substitutes. The positive and significant double interaction term, in turn, shows that this phenomenon is less likely at upstream stages, and therefore occurs downstream. Moreover, the significantly negative interaction between complementarity and upstreamness confirms that the Slovenian sample is consistent with Antràs and Chor (2013) prediction in that likelihood of integration decreases with moving upstream the production chain for complements, compared to the substitutes where the impact of the upstreamness on integration is positive, yet insignificant.

Splitting the sample (Table 3) allows us to see in a more direct manner that the statistical significance of the coefficients of IPR protection and its interaction with upstreamness are in fact only true for the case of sequential complements which is in line with the model prediction 3 stating the IPRs bear more relevant implications for the sequential complements. Again, IPRs tend to reduce the propensity to integrate (significantly negative coefficient for IPRs in all specifications), and this tends to be the case for relatively downstream stages as denoted with the positive coefficient of the interaction between IPRs and upstreamness, which becomes weakly significant once the firmcounty-product effects are controlled for in the random effects specification in column (5). This result presents a support for the model prediction 1. Regarding the effect of the position along the value chain, again the impact of upstreamness on integration versus outsourcing decision differs for complements and substitutes (confirmed based on Chow test of equality of regression coefficients between two groups); the impact of upstreamness is, in line with Antràs and Chor (2013), significantly negative for complements whereas for substitutes the regression coefficient is insignficiant.

The controlling firm-specific explanatory variables of vertical integration are largely in line with the theoretical expectations. Results indicate that larger and older firms with higher export propensity are more likely on average to integrate inputs, all else being equal, as confirmed by positive and significant regression coefficients in most specifications for both complements and substitutes. The only exception are the Mundlak/Chamberlain/Wooldridge-type specifications (3) and (4) in Table 3, where the period averages take up the effect of export propensity. This explains as well the insignificant impact of the export propensity in aggregate sample specification (2) from Table 2. On the other hand, capital intensity of a firm's production process proves to have the opposite impact on integration versus outsourcing decision for complements and substitutes, namely positive for complements and negative for substitutes. Such difference in the impact on the incidence of integration between complements and substitutes is observed as well for labor productivity in random effects specifications (5-6), but the results are not robust. The heterogeneous effect of the capital intensity and firm productivity provides a plausible explanation for their less consistent impact in aggregate sample specifications that pool together both sequential complements and substitutes. Firm's financial leverage measured by debt to assets ratio tends to exhibit negative effect on the 
Table 2: Probit and random effects (RE) probit model of integration at firm-market-product level for pooled sample - triple interaction specification, rho measure

\begin{tabular}{|c|c|c|c|}
\hline & $\begin{array}{c}\text { (1) } \\
\text { probit } \\
\text { Rho }\end{array}$ & $\begin{array}{c}\text { (2) } \\
\text { probit } \\
\text { Chamberlain-Mundlack } \\
\text { Rho }\end{array}$ & $\begin{array}{c}\text { (3) } \\
\text { RE probit } \\
\text { Rho }\end{array}$ \\
\hline & Rho & Rho & Rho \\
\hline \multirow{4}{*}{$\begin{array}{l}\text { d_compl } \\
1 \\
\operatorname{lnIPR}\end{array}$} & $11.820 * *$ & $12.352^{* *}$ & $27.145^{* * *}$ \\
\hline & $(5.494)$ & $(5.565)$ & $(9.455)$ \\
\hline & 0.705 & 0.879 & -2.120 \\
\hline & $(2.332)$ & $(2.538)$ & $(4.196)$ \\
\hline \multirow{2}{*}{$\begin{array}{l}\text { d_compl \# } \ln I P R \\
1\end{array}$} & $-7.712^{* *}$ & $-8.067 * *$ & $-17.495 * * *$ \\
\hline & $(3.757)$ & $(3.796)$ & $(6.329)$ \\
\hline \multirow[t]{2}{*}{ Upstr } & 0.639 & 0.669 & 0.419 \\
\hline & $(0.916)$ & $(0.910)$ & $(2.292)$ \\
\hline d_compl \# Upstr & $-6.508^{*}$ & $-6.831^{*}$ & $-13.076^{* *}$ \\
\hline 1 & $(3.519)$ & $(3.620)$ & $(5.983)$ \\
\hline \multirow[t]{2}{*}{$\operatorname{lnIPR\# ~Upstr}$} & -0.587 & -0.608 & -0.645 \\
\hline & $(0.679)$ & $(0.674)$ & $(1.577)$ \\
\hline \multirow{2}{*}{ 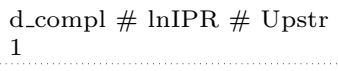 } & $4.242^{*}$ & $4.451^{*}$ & $8.476^{* *}$ \\
\hline & $(2.330)$ & $(2.392)$ & $(3.980)$ \\
\hline $\ln \operatorname{Size}(-1)$ & $\begin{array}{c}0.147^{* * * *} \\
(0.050)\end{array}$ & $\begin{array}{c}0.880 * * \\
(0.362)\end{array}$ & $\begin{array}{c}0.529 * * * \\
(0.194)\end{array}$ \\
\hline \multirow[t]{2}{*}{ Age } & $0.046^{* * *}$ & $0.047 * * *$ & $0.214^{* * *}$ \\
\hline & $(0.016)$ & $(0.016)$ & $(0.027)$ \\
\hline \multirow[t]{2}{*}{ Ex_propensity(-1) } & $1.217^{* * *}$ & -0.512 & $5.528^{* * *}$ \\
\hline & $(0.302)$ & $(0.746)$ & $(0.631)$ \\
\hline \multirow{2}{*}{$\operatorname{lnK}$ _intensity(-1) } & -0.037 & 0.221 & $-0.418^{* *}$ \\
\hline & $(0.144)$ & $(0.234)$ & $(0.187)$ \\
\hline \multirow[t]{2}{*}{ lnL_productivity(-1) } & 0.100 & $0.593^{* * *}$ & $0.562^{* *}$ \\
\hline & $(0.095)$ & $(0.225)$ & $(0.229)$ \\
\hline \multirow{2}{*}{ Debt_assets(-1) } & -0.682 & -0.618 & 0.419 \\
\hline & $(0.454)$ & $(0.621)$ & $(0.661)$ \\
\hline lnSize_avg & & $\begin{array}{c}-0.738^{* *} \\
(0.351)\end{array}$ & \\
\hline \multirow[t]{2}{*}{ Ex_propensity_avg } & & $1.840^{* *}$ & \\
\hline & & $(0.801)$ & \\
\hline \multirow[t]{2}{*}{ lnK_intensity_avg } & & -0.248 & \\
\hline & & $(0.240)$ & \\
\hline \multirow[t]{2}{*}{ lnL_productivity_avg } & & $-0.492^{* *}$ & \\
\hline & & $(0.228)$ & \\
\hline \multirow{2}{*}{ Debt_assets_avg } & & -0.140 & \\
\hline & & $(0.610)$ & \\
\hline \multirow[t]{2}{*}{$\ln$ Dist } & & & -0.053 \\
\hline & & & $(0.167)$ \\
\hline $\ln G D P$ & & & -0.026 \\
\hline \multirow{2}{*}{$\operatorname{lnGDPpc}$} & & & $(0.126)$ \\
\hline & & & -0.351 \\
\hline \multirow{2}{*}{ Constant } & & & \\
\hline & $\begin{array}{c}-7.534^{* *} \\
(3.469) \\
\end{array}$ & $\begin{array}{c}-7.980^{* *} \\
(3.789) \\
\end{array}$ & $\begin{array}{c}-21.064^{* * *} \\
(6.578)\end{array}$ \\
\hline Log pse.likelihood & -1473.0456 & -1460.1338 & -1011.909 \\
\hline Wald test & $\operatorname{chi} 2(40)=$ & $\operatorname{chi} 2(45)=$ & $\operatorname{chi} 2(19)=$ \\
\hline & $3265.54 * * *$ & $3607.38^{* * *}$ & $264.28^{* * *}$ \\
\hline Wald's test for heteroskeda & icity (HO: $\ln$ & $\operatorname{gma} 2=0)$ & \\
\hline $\operatorname{lnsigma2}$ & 0.004 & 0.005 & \\
\hline lempllag & $(0.054)$ & $(0.060)$ & \\
\hline $\operatorname{chi} 2(1)$ & 0.01 & 0.01 & \\
\hline Likelihood-ratio test; rho $=$ & $\operatorname{chi} 2(1)(\operatorname{Prc}$ & $>\operatorname{chi} 2)$ & \\
\hline & & & $1537.89^{* * *}$ \\
\hline Observations & 625,799 & 625,623 & 804,115 \\
\hline N. of firm-market-product & & & 450,923 \\
\hline
\end{tabular}

Note: Robust Std. Err. in round brackets, adjusted for firm clusters in (heteroskedastic) probit models; *** $p<0.01,{ }^{* *} p<0.05,{ }^{*} p<0.1$. 
Table 3: Probit and random effects (RE) probit model of integration at firm-market-product level, rho measure

\begin{tabular}{|c|c|c|c|c|c|c|}
\hline & $\begin{array}{l}(1) \\
\text { probit }\end{array}$ & $\begin{array}{c}(2) \\
\text { het.probit }\end{array}$ & $\begin{array}{c}\text { (3) } \\
\text { probit } \\
\text { Chamberlain } \\
\text {-Mundlack }\end{array}$ & $\begin{array}{c}\text { (4) } \\
\text { probit } \\
\text { Chamberlain } \\
\text {-Mundlack }\end{array}$ & $\begin{array}{c}(5) \\
\text { RE probit }\end{array}$ & $\begin{array}{c}(6) \\
\text { RE probit }\end{array}$ \\
\hline & Compl & Subst & Compl & Subst & Compl & Subst \\
\hline $\ln I P R$ & $\begin{array}{c}-9.164^{* * *} \\
(3.379)\end{array}$ & $\begin{array}{c}0.347 \\
(1.694)\end{array}$ & $\begin{array}{c}-9.281^{* *} \\
(3.705)\end{array}$ & $\begin{array}{c}0.012 \\
(1.631)\end{array}$ & $\begin{array}{l}-25.62^{* * *} \\
(5.808)\end{array}$ & $\begin{array}{l}-1.125 \\
(6.074)\end{array}$ \\
\hline Upstr & $\begin{array}{c}-6.850^{*} \\
(4.068)\end{array}$ & $\begin{array}{c}0.071 \\
(0.668)\end{array}$ & $\begin{array}{l}-7.157^{*} \\
(4.131)\end{array}$ & $\begin{array}{c}0.061 \\
(0.653)\end{array}$ & $\begin{array}{c}-13.680^{*} \\
(7.220)\end{array}$ & $\begin{array}{l}-0.165 \\
(3.788)\end{array}$ \\
\hline lnIPR \# Upstr & $\begin{array}{c}4.258 \\
(2.675)\end{array}$ & $\begin{array}{l}-0.124 \\
(0.496)\end{array}$ & $\begin{array}{c}4.460 \\
(2.717)\end{array}$ & $\begin{array}{l}-0.117 \\
(0.485)\end{array}$ & $\begin{array}{l}8.078^{*} \\
(4.758)\end{array}$ & $\begin{array}{l}-0.473 \\
(2.593)\end{array}$ \\
\hline $\operatorname{lnSize}(1)$ & $\begin{array}{c}0.265^{* * *} \\
(0.086)\end{array}$ & $\begin{array}{c}0.272^{* * *} \\
(0.086)\end{array}$ & $\begin{array}{l}0.983^{*} \\
(0.543)\end{array}$ & $\begin{array}{c}0.816^{* * * *} \\
(0.205)\end{array}$ & $\begin{array}{c}1.185^{* * *} \\
(0.309)\end{array}$ & $\begin{array}{c}1.645^{* * *} \\
(0.308)\end{array}$ \\
\hline Age & $\begin{array}{c}0.044^{* * *} \\
(0.013)\end{array}$ & $\begin{array}{c}0.023^{* *} \\
(0.013)\end{array}$ & $\begin{array}{c}0.041^{* * *} \\
(0.010)\end{array}$ & $\begin{array}{c}0.023^{* *} \\
(0.009)\end{array}$ & $\begin{array}{l}0.250^{* * *} \\
(0.0648)\end{array}$ & $\begin{array}{l}0.295 * * * \\
(0.0397)\end{array}$ \\
\hline Ex_propensity(-1) & $\begin{array}{c}1.312^{* * *} \\
(0.357)\end{array}$ & $\begin{array}{c}0.577^{* *} \\
(0.357)\end{array}$ & $\begin{array}{l}-0.708 \\
(0.825)\end{array}$ & $\begin{array}{l}-0.178 \\
(0.927)\end{array}$ & $\begin{array}{c}8.076^{* * *} \\
(1.353)\end{array}$ & $\begin{array}{c}4.208^{* * *} \\
(1.019)\end{array}$ \\
\hline lnK_intensity $(-1)$ & $\begin{array}{c}0.472^{* * * *} \\
(0.125)\end{array}$ & $\begin{array}{c}-0.138^{* *} \\
(0.125)\end{array}$ & $\begin{array}{l}0.678^{*} \\
(0.366)\end{array}$ & $\begin{array}{l}-0.033 \\
(0.092)\end{array}$ & $\begin{array}{l}0.0986 \\
(0.497)\end{array}$ & $\begin{array}{c}-1.853^{* * *} \\
(0.288)\end{array}$ \\
\hline lnL_productivity(-1) & $\begin{array}{l}-0.002 \\
(0.148)\end{array}$ & $\begin{array}{c}-0.270^{* *} \\
(0.148)\end{array}$ & $\begin{array}{c}0.264 \\
(0.282)\end{array}$ & $\begin{array}{c}0.065 \\
(0.264)\end{array}$ & $\begin{array}{l}1.141^{* *} \\
(0.479)\end{array}$ & $\begin{array}{l}0.0254 \\
(0.454)\end{array}$ \\
\hline debt_asset $(-1)$ & $\begin{array}{c}-1.291^{* *} \\
(0.578)\end{array}$ & $\begin{array}{l}-0.295 \\
(0.578)\end{array}$ & $\begin{array}{l}-0.102 \\
(0.829)\end{array}$ & $\begin{array}{l}-0.315 \\
(0.252)\end{array}$ & $\begin{array}{l}-2.251 \\
(1.704)\end{array}$ & $\begin{array}{l}-0.985 \\
(1.325)\end{array}$ \\
\hline $\ln$ Dist & & & & & $\begin{array}{c}0.230 \\
(0.365)\end{array}$ & $\begin{array}{l}-0.221 \\
(0.340)\end{array}$ \\
\hline $\ln G D P$ & & & & & $\begin{array}{c}0.530 \\
(0.328)\end{array}$ & $\begin{array}{c}-0.424^{* *} \\
(0.211)\end{array}$ \\
\hline $\operatorname{lnGDPpc}$ & & & & & $\begin{array}{l}-0.205 \\
(0.558)\end{array}$ & $\begin{array}{l}-0.871 \\
(0.584)\end{array}$ \\
\hline lnSize_avg & & & $\begin{array}{l}-0.702 \\
(0.527)\end{array}$ & $\begin{array}{c}-0.546^{* * *} \\
(0.209)\end{array}$ & & \\
\hline Ex_propensity_avg & & & $\begin{array}{c}2.103^{* * *} \\
(0.791)\end{array}$ & $\begin{array}{c}0.821 \\
(0.856)\end{array}$ & & \\
\hline lnK_intensity_avg & & & $\begin{array}{l}-0.189 \\
(0.345)\end{array}$ & $\begin{array}{l}-0.109 \\
(0.096)\end{array}$ & & \\
\hline lnP_productivity_avg & & & $\begin{array}{l}-0.234 \\
(0.240)\end{array}$ & $\begin{array}{c}-0.341 \\
(0.227)\end{array}$ & & \\
\hline debt_asset_avg & & & $\begin{array}{l}-1.356 \\
(1.064)\end{array}$ & $\begin{array}{c}0.025 \\
(0.018)\end{array}$ & & \\
\hline Constant & $\begin{array}{c}4.090 \\
(5.475) \\
\end{array}$ & & $\begin{array}{c}3.644 \\
(6.116) \\
\end{array}$ & $\begin{array}{l}-0.221 \\
(3.522)\end{array}$ & $\begin{array}{l}-23.09^{*} \\
(12.64)\end{array}$ & $\begin{array}{l}-0.116 \\
(10.77)\end{array}$ \\
\hline Country dummies & yes & yes & yes & yes & no & no \\
\hline time dummies & yes & yes & yes & yes & yes & yes \\
\hline Industry dummies & yes & yes & yes & yes & no & no \\
\hline Log pse.likelihood & -461.23776 & -815.8606 & -455.4313 & -810.2111 & -407.63711 & -537.90789 \\
\hline Wald test & $\begin{array}{c}\operatorname{chi} 2(32)= \\
12383.99 *\end{array}$ & $\begin{array}{c}\operatorname{chi} 2(28)= \\
538.01^{* * *}\end{array}$ & $\begin{array}{c}\operatorname{chi} 2(37)= \\
26385.75^{* * *}\end{array}$ & $\begin{array}{c}\operatorname{chi} 2(33)= \\
1089.99^{* * *}\end{array}$ & $\begin{array}{c}\operatorname{chi} 2(15)= \\
155.38 * * *\end{array}$ & $\begin{array}{c}\operatorname{chi} 2(15)= \\
222.89 * * *\end{array}$ \\
\hline $\begin{array}{l}\text { Wald's test for heteroskeda } \\
\text { lnsigma } 2 \\
\text { lempllag } \\
\text { chi2 }(1)\end{array}$ & $\begin{array}{c}\text { icity }(\mathrm{H} 0: \ln \\
0.106 \\
(0.099) \\
1.15\end{array}$ & $\begin{array}{c}\operatorname{gma} 2=0) \\
-0.101 * * * \\
(0.037) \\
7.47 * * *\end{array}$ & $\begin{array}{c}0.109 \\
(0.109) \\
1.01\end{array}$ & $\begin{array}{l}-0.102^{* * *} \\
(0.040) \\
7.20^{* * *}\end{array}$ & & \\
\hline \multicolumn{7}{|c|}{ Likelihood-ratio test; rho $=0: \operatorname{chi} 2(1)($ Prob $>\operatorname{chi} 2)$} \\
\hline Observations & 251,719 & 316922 & 251,688 & 316,778 & 346,548 & 457,567 \\
\hline N. of firm-market-product & & & & & 220,603 & 279,576 \\
\hline
\end{tabular}

Note: Robust Std. Err. in round brackets, adjusted for firm clusters in (heteroskedastic) probit models; *** $p<0.01,{ }^{* *} p<0.05,{ }^{*} p<0.1$.

likelihood of integration but the impact is found to be insignificant in several specifications.

To better visualize the impact of IPRs we present two figures based on specifications (1) and 
(2) from Table 3. Figure 5 plots predicted probabilities of integration for complements at different stages along the supply chain for low and high value of Park's IPR index, while Figure 6 represents average marginal effect of an increase in Park's measure $(\operatorname{lnI} P R)$ on probability to integrate at different stages along the supply chain for complements and substitutes.

Figure 5: Predictive margins

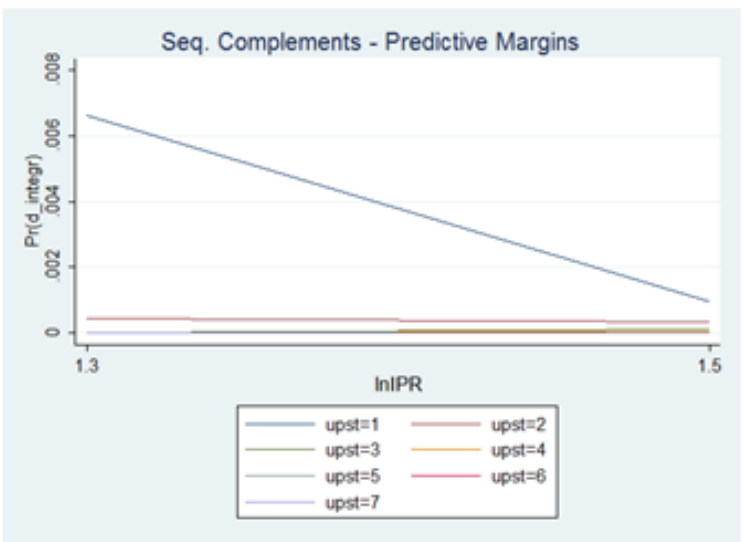

Notes: Based on regression from Table 3, column 1 (Table 3, column 1)

Figure 6: (Average) Marginal effects of the level of IPR protection
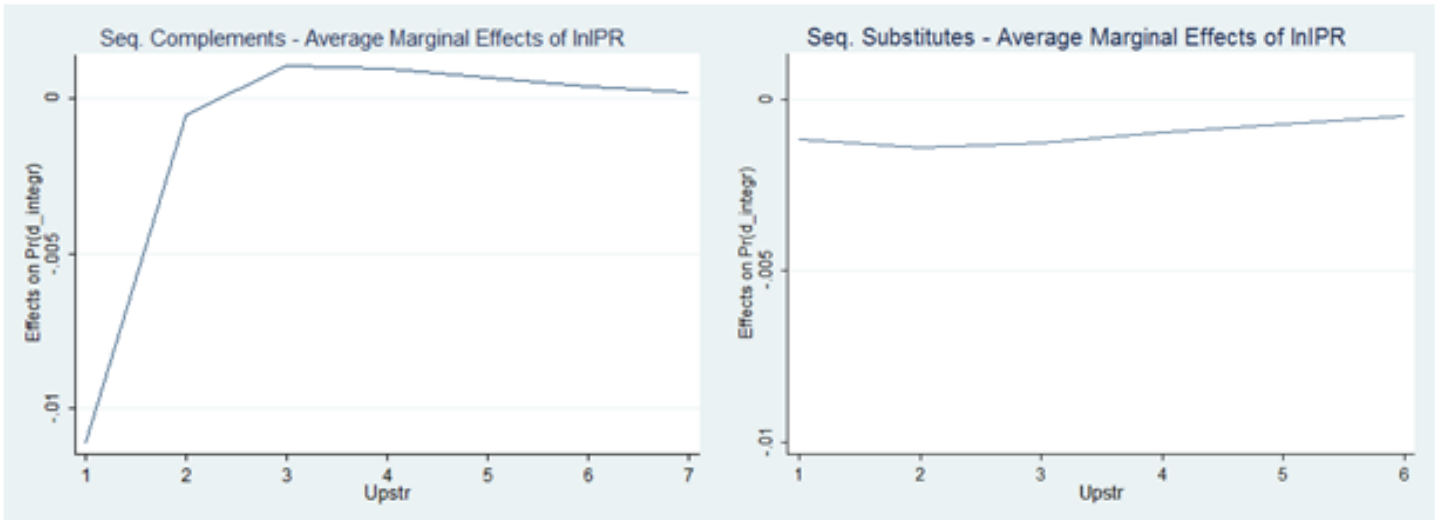

Notes: Based on regression from Table 3, columns 1-2; the IPR variable is here expressed as the log of the Park index.

Putting the figures alongside the Tables 2 and 3 suggest that IPR protection bears a heterogeneous impact on producers' propensity to integrate suppliers with respect to their position in the supply chain and sequential complementarity/substitutability of their investments. More specifically, improvement in the level of IPR protection decreases the likelihood of integration of the suppliers in more downstream parts of the production process (for low value of Upstr) in industries in which suppliers' investments along the value chain are sequential complements (as depicted by negative 
values of the marginal effects in Figure 5 for the most downstream positions and decreasing curve for complements in the downstream stages in Figure 6). We instead observe no significant effect on the propensity to integrate in more upstream stages under sequential complements and at all stages when inputs are sequential substitutes, which explains the irrelevance of IPRs in the latter case. These results reinforce the hypothesis that things may differ with respect to the organizational decision of firms when studying intangible assets under the property rights approach. Imitation and IPRs are important factors in the organizational decision of firms along the supply chain, and that they do not coincide with decisions based on the contractual environment. Recall that under the property right theory for tangible assets we expect contract enforcement to increase the prevalence of integration over outsourcing. We can also deduce from these results that our findings are specific to IPR protection and cannot be generalized to other regulatory measure that directly affect contract enforcement.

Table 4 replicates the same regressions from Table 3 but replaces the IPR index with a measure of the Rule of law from the Worldwide Governance Indicators (2015) database to see how things fair for contract enforcement in a property right environment. The results clearly show the opposite impact for rule of law on firm integration decision, i.e. significantly negative impact for substitutes in all specifications and positive effect for complements which is significant in specifications (1) and (3) while insignificant in random effect probit specification from column (5). The interaction term between rule of law and upstreamness is not significant in neither of specifications from Table 4.

In Table 5 we finally present the results based on three alternative approaches for identification of the sequential complements and substitutes to the one based on $\rho$ (import demand elasticities) which we rely on in Tables 2 and 3. In columns (1)-(2) on Table 5 we use industry-average value of the Herfindahl index as a proxy for (inverse) $\alpha$ to distinguish between complements and substitutes (d_complalpha_ind $)$. Next, in columns (3)-(4) sequential substitutes/complements identification is carried out by considering both $\rho$ (import demand elasticity) and industry averages of Herfindahl index to determine sequential complements/substitutes ( $d_{-}$compl $_{\text {rho_alpha_ind }}$ ), while in columns (5)(6), specifications are based on the difference between $\rho$ and the $\alpha$ measure estimated based on demand elasticities of the intermediate and capital good imported inputs (d_compl $l_{\text {rho_alpha_elast }}$ ). We employ random effects probit estimator that allows controlling for unobserved heterogeneity at detailed firm-county-product level. Likelihood-ratio test rejects the hypothesis of $\rho=0$ in all specifications and confirms the importance of the unobserved heterogeneity ("frailty") in this sub-sample. Hence, we proceed with the interpretation of random effects probit results.

Results show that our findings from Tables 2 and 3 are fully robust to these alternative ways of separating complements and substitutes. The impact of the effectiveness of the protection of IPRs is significantly negative in all specifications for the case of complements. Moreover, the interaction term with upstreamness becomes even more significant reinforcing our expectation of the more important 
Table 4: Probit and random effects (RE) probit model of integration at firm-market-product level with Rule of law, rho measure

\begin{tabular}{|c|c|c|c|c|c|c|}
\hline & $\begin{array}{l}(1) \\
\text { probit }\end{array}$ & $\begin{array}{c}\text { (2) } \\
\text { het.probit }\end{array}$ & $\begin{array}{c}(3) \\
\text { probit } \\
\text { Chamberlain } \\
\text {-Mundlack }\end{array}$ & $\begin{array}{c}\text { (4) } \\
\text { het.probit } \\
\text { Chamberlain } \\
\text {-Mundlack }\end{array}$ & $\begin{array}{c}(5) \\
\text { RE probit }\end{array}$ & $\begin{array}{c}(6) \\
\text { RE probit }\end{array}$ \\
\hline & Compl & Subst & Compl & Subst & Compl & Subst \\
\hline Rule_of_law & $\begin{array}{l}1.276^{* *} \\
(0.643)\end{array}$ & $\begin{array}{c}-0.537^{* *} \\
(0.252)\end{array}$ & $\begin{array}{l}1.296^{* *} \\
(0.607)\end{array}$ & $\begin{array}{c}-0.578^{* *} \\
(0.262)\end{array}$ & $\begin{array}{l}-0.735 \\
(0.554)\end{array}$ & $\begin{array}{c}-1.464^{* *} \\
(0.685)\end{array}$ \\
\hline Upstr & $\begin{array}{l}-0.059 \\
(0.142)\end{array}$ & $\begin{array}{c}-0.120^{*} \\
(0.064)\end{array}$ & $\begin{array}{l}-0.057 \\
(0.141)\end{array}$ & $\begin{array}{c}-0.119^{*} \\
(0.067)\end{array}$ & $\begin{array}{c}-0.649 * * * \\
(0.206)\end{array}$ & $\begin{array}{c}-0.823^{* * *} * \\
(0.218)\end{array}$ \\
\hline Rule_of_law \# Upstr & $\begin{array}{c}-0.168 \\
(0.111)\end{array}$ & $\begin{array}{c}0.025 \\
(0.034)\end{array}$ & $\begin{array}{l}-0.170 \\
(0.111)\end{array}$ & $\begin{array}{c}0.024 \\
(0.035)\end{array}$ & $\begin{array}{c}-0.256 \\
(0.217)\end{array}$ & $\begin{array}{c}0.026 \\
(0.236)\end{array}$ \\
\hline $\operatorname{lnSize}(-1)$ & $\begin{array}{c}0.174^{* * *} \\
(0.061)\end{array}$ & $\begin{array}{c}0.219^{* * *} \\
(0.030)\end{array}$ & $\begin{array}{l}0.672^{*} \\
(0.361)\end{array}$ & $\begin{array}{c}0.372^{* *} \\
(0.148)\end{array}$ & $\begin{array}{c}0.760^{* * * *} \\
(0.150)\end{array}$ & $\begin{array}{c}0.954^{* * *} \\
(0.130)\end{array}$ \\
\hline Age & $\begin{array}{l}0.019^{* *} \\
(0.008)\end{array}$ & $\begin{array}{c}0.018^{* * *} * \\
(0.005)\end{array}$ & $\begin{array}{l}0.018^{* *} \\
(0.008)\end{array}$ & $\begin{array}{c}0.017^{* * *} * \\
(0.005)\end{array}$ & $\begin{array}{c}0.132^{* * * *} \\
(0.029)\end{array}$ & $\begin{array}{c}0.162^{* * *} \\
(0.026)\end{array}$ \\
\hline Ex_propensity(-1) & $\begin{array}{c}1.446^{* * *} \\
(0.257)\end{array}$ & $\begin{array}{c}0.402^{* * *} * \\
(0.135)\end{array}$ & $\begin{array}{c}0.217 \\
(0.701)\end{array}$ & $\begin{array}{l}-0.698 \\
(0.486)\end{array}$ & $\begin{array}{c}6.427^{* * *} \\
(0.659)\end{array}$ & $\begin{array}{c}3.244^{* * *} * \\
(0.705)\end{array}$ \\
\hline lnK_intensity(-1) & $\begin{array}{c}0.270^{* * *} \\
(0.092)\end{array}$ & $\begin{array}{l}-0.051 \\
(0.065)\end{array}$ & $\begin{array}{l}0.377^{* *} \\
(0.151)\end{array}$ & $\begin{array}{l}-0.079 \\
(0.072)\end{array}$ & $\begin{array}{c}0.881^{* * * *} \\
(0.266)\end{array}$ & $\begin{array}{c}-0.643^{* * *} \\
(0.241)\end{array}$ \\
\hline $\operatorname{lnL}$ _productivity $(-1)$ & $\begin{array}{c}0.113 \\
(0.087)\end{array}$ & $\begin{array}{c}-0.247 * * * \\
(0.085)\end{array}$ & $\begin{array}{c}0.131 \\
(0.192)\end{array}$ & $\begin{array}{l}-0.130 \\
(0.144)\end{array}$ & $\begin{array}{c}0.674^{* * * *} \\
(0.234)\end{array}$ & $\begin{array}{c}-0.812^{* * *} \\
(0.287)\end{array}$ \\
\hline Debt_assets $(-1)$ & $\begin{array}{c}-0.810^{* *} \\
(0.367)\end{array}$ & $\begin{array}{c}-0.231 \\
(0.201)\end{array}$ & $\begin{array}{c}-0.459 \\
(0.732)\end{array}$ & $\begin{array}{l}-0.218 \\
(0.230)\end{array}$ & $\begin{array}{c}-1.928^{* *} \\
(0.917)\end{array}$ & $\begin{array}{c}-0.172 \\
(0.899)\end{array}$ \\
\hline $\operatorname{lnDist}$ & & & & & $\begin{array}{c}-0.581^{*} \\
(0.307)\end{array}$ & $\begin{array}{c}-0.964 * * * \\
(0.345)\end{array}$ \\
\hline $\ln G D P$ & & & & & $\begin{array}{c}-0.379 * * \\
(0.163)\end{array}$ & $\begin{array}{c}0.747^{* * *} \\
(0.186)\end{array}$ \\
\hline $\operatorname{lnGDPpc}$ & & & & & $\begin{array}{c}-1.518^{* * *} \\
(0.590)\end{array}$ & $\begin{array}{c}-1.619^{* *} \\
(0,717)\end{array}$ \\
\hline lnSize_avg & & & $\begin{array}{l}-0.499 \\
(0.337)\end{array}$ & $\begin{array}{l}-0.159 \\
(0.151)\end{array}$ & & \\
\hline Ex_propensity_avg & & & $\begin{array}{l}1.259^{*} \\
(0.748)\end{array}$ & $\begin{array}{l}1.174^{* *} * \\
(0.521)\end{array}$ & & \\
\hline lnK_intensity_avg & & & $\begin{array}{l}-0.095 \\
(0.145)\end{array}$ & $\begin{array}{c}0.031 \\
(0.098)\end{array}$ & & \\
\hline lnL_productivity_avg & & & $\begin{array}{l}-0.001 \\
(0.148)\end{array}$ & $\begin{array}{l}-0.113 \\
(0.138)\end{array}$ & & \\
\hline Debt_assets_avg & & & $\begin{array}{c}-0.412 \\
(0.686)\end{array}$ & $\begin{array}{c}-0.002 \\
(0.091)\end{array}$ & & \\
\hline Constant & $\begin{array}{c}-10.196^{* * *} \\
(1.276)\end{array}$ & $\begin{array}{l}-0.273 \\
(1.521)\end{array}$ & $\begin{array}{c}-10.523 * * * \\
(1.303)\end{array}$ & $\begin{array}{l}-0.328 \\
(1.565)\end{array}$ & $\begin{array}{c}-12.240^{* *} \\
(5.270)\end{array}$ & $\begin{array}{c}26.729^{* * *} \\
(7.513)\end{array}$ \\
\hline Country dummies & yes & yes & yes & yes & no & no \\
\hline Time dummies & yes & yes & yes & yes & yes & yes \\
\hline Industry dummies & yes & yes & yes & yes & no & no \\
\hline Log pse.likelihood & -1261.2475 & -1582.473 & -1254.7063 & -1574.093 & -815.9058 & -875.1844 \\
\hline Wald test & $\begin{array}{c}\operatorname{chi} 2(39)= \\
9017.75^{* * *}\end{array}$ & $\begin{array}{c}\operatorname{chi} 2(33)= \\
1097.95^{* * *}\end{array}$ & $\begin{array}{c}\operatorname{chi} 2(39)= \\
9064.68^{* * *}\end{array}$ & $\begin{array}{c}\operatorname{chi} 2(38)= \\
1193.74^{* * *}\end{array}$ & $\begin{array}{c}\operatorname{chi} 2(15)= \\
261.95^{* * *}\end{array}$ & $\begin{array}{c}\operatorname{chi} 2(15)= \\
364.50 * * *\end{array}$ \\
\hline $\begin{array}{l}\text { Wald's test for heteroskeda } \\
\text { lnsigma2 } \\
\quad \text { lempllag } \\
\text { chi2 }(1)\end{array}$ & $\begin{array}{c}\text { ticity (H0: } \ln \\
-0.013 \\
(0.048) \\
0.08\end{array}$ & $\begin{array}{c}\operatorname{gma} 2=0) \\
-0.093^{* * *} \\
(0.032) \\
8.66^{* * *}\end{array}$ & $\begin{array}{c}-0.013 \\
(0.048) \\
0.07\end{array}$ & $\begin{array}{c}-0.092 * * * \\
(0.034) \\
7.33^{* * *}\end{array}$ & & \\
\hline \multicolumn{7}{|c|}{ Likelihood-ratio test; $r h o=0: \operatorname{chi} 2(1)($ Prob $>\operatorname{chi} 2)$} \\
\hline $\begin{array}{l}\text { Observations } \\
\text { N. of firm-market-product }\end{array}$ & 282,818 & 368,206 & 282,771 & 368,060 & $\begin{array}{l}361,415 \\
230,738\end{array}$ & $\begin{array}{r}475099 \\
291,317\end{array}$ \\
\hline
\end{tabular}

Note: Robust Std. Err. in round brackets, adjusted for firm clusters in (heteroskedastic) probit models; *** $p<0.01,{ }^{* *} p<0.05,{ }^{*} p<0.1$.

role of IPRs in downstream stages of the production process. The results indicate that outsourcing becomes more likely with improved IPR, which holds for the relatively downstream stages as denoted 
Table 5: Random effects probit model of integration at firm-market-product level, industry-level Alpha and combined Rho_Alpha_ind and Rho_Alpha_elast (Alfaro et al.) measures

\begin{tabular}{|c|c|c|c|c|c|c|}
\hline & $\begin{array}{c}\text { (1) } \\
\text { Alpha_ind } \\
\text { Compl }\end{array}$ & $\begin{array}{c}(2) \\
\text { Alpha_ind } \\
\text { Subst }\end{array}$ & $\begin{array}{c}(3) \\
\text { Rho_- } \\
\text { Alpha_ind } \\
\text { Compl }\end{array}$ & $\begin{array}{c}\text { (4) } \\
\text { Rho_- } \\
\text { Alpha_ind } \\
\text { Subst }\end{array}$ & $\begin{array}{c}(5) \\
\text { Rho_ } \\
\text { Alpha_elast } \\
\text { Compl }\end{array}$ & $\begin{array}{c}\text { (6) } \\
\text { Rho_ } \\
\text { Alpha_elast } \\
\text { Subst }\end{array}$ \\
\hline $\operatorname{lnIPR}$ & $\begin{array}{c}-11.374 * * * \\
(2.442)\end{array}$ & $\begin{array}{l}-2.568 \\
(4.404)\end{array}$ & $\begin{array}{c}-18.966^{* * *} \\
(3.148)\end{array}$ & $\begin{array}{l}-0.808 \\
(4.360)\end{array}$ & $\begin{array}{c}-16.867^{* * *} \\
(2.716)\end{array}$ & $\begin{array}{c}0.786 \\
(3.800)\end{array}$ \\
\hline Upstr & $\begin{array}{c}-4.577^{* *} \\
(2.069)\end{array}$ & $\begin{array}{c}1.164 \\
(2.672)\end{array}$ & $\begin{array}{c}-8.553 * * * \\
(2.875)\end{array}$ & $\begin{array}{c}0.266 \\
(2.590)\end{array}$ & $\begin{array}{c}-8.186 * * * \\
(2.634)\end{array}$ & $\begin{array}{c}0.606 \\
(2.040)\end{array}$ \\
\hline $\operatorname{lnIPR} \#$ Upstr & $\begin{array}{l}2.744^{* *} \\
(1.398)\end{array}$ & $\begin{array}{l}-1.609 \\
(1.829)\end{array}$ & $\begin{array}{c}5.430 * * * \\
(1.911)\end{array}$ & $\begin{array}{c}-0.940 \\
(1.765)\end{array}$ & $\begin{array}{c}5.092^{* * *} \\
(1.771)\end{array}$ & $\begin{array}{c}-0.771 \\
(1.384)\end{array}$ \\
\hline $\ln \operatorname{Size}(-1)$ & $\begin{array}{c}0.348^{* * * *} \\
(0.107)\end{array}$ & $\begin{array}{c}1.266^{* * * *} \\
(0.168)\end{array}$ & $\begin{array}{c}0.496^{* * * *} \\
(0.142)\end{array}$ & $\begin{array}{c}0.414^{* * * *} \\
(0.137)\end{array}$ & $\begin{array}{c}0.747 * * * \\
(0.178)\end{array}$ & $\begin{array}{c}0.375 * * * \\
(0.109)\end{array}$ \\
\hline Age & $\begin{array}{c}0.191^{* * *} \\
(0.024)\end{array}$ & $\begin{array}{l}-0.002 \\
(0.023)\end{array}$ & $\begin{array}{c}0.385^{* * *} * \\
(0.036)\end{array}$ & $\begin{array}{c}0.039^{* *} \\
(0.019)\end{array}$ & $\begin{array}{c}0.338^{* * *} \\
(0.049)\end{array}$ & $\begin{array}{c}0.139 * * * \\
(0.022)\end{array}$ \\
\hline Ex_propensity(-1) & $\begin{array}{c}4.815^{* * *} \\
(0.657)\end{array}$ & $\begin{array}{c}8.127 * * * \\
(1.394)\end{array}$ & $\begin{array}{c}9.464^{* * *} \\
(1.186)\end{array}$ & $\begin{array}{l}1.317^{* *} * \\
(0.630)\end{array}$ & $\begin{array}{c}8.656^{* * *} \\
(1.046)\end{array}$ & $\begin{array}{c}3.811 * * * \\
(0.657)\end{array}$ \\
\hline lnK_intensity(-1) & $\begin{array}{c}-0.420^{* *} \\
(0.172)\end{array}$ & $\begin{array}{c}0.195 \\
(0.244)\end{array}$ & $\begin{array}{l}-0.586^{*} \\
(0.314)\end{array}$ & $\begin{array}{c}0.026 \\
(0.217)\end{array}$ & $\begin{array}{c}-0.732^{* * *} * \\
(0.259)\end{array}$ & $\begin{array}{l}-0.214 \\
(0.189)\end{array}$ \\
\hline $\operatorname{lnL}$ _productivity $(-1)$ & $\begin{array}{c}0.583^{* * *} * \\
(0.192)\end{array}$ & $\begin{array}{c}0.340 \\
(0.293)\end{array}$ & $\begin{array}{c}1.036^{* * * *} \\
(0.359)\end{array}$ & $\begin{array}{l}-0.296 \\
(0.251)\end{array}$ & $\begin{array}{c}1.425^{* * *} * \\
(0.331)\end{array}$ & $\begin{array}{c}0.299 \\
(0.204)\end{array}$ \\
\hline Debt_assets (-1) & $\begin{array}{c}0.318 \\
(0.573)\end{array}$ & $\begin{array}{c}1.846^{* * *} \\
(0.248)\end{array}$ & $\begin{array}{c}-2.654^{* *} \\
(1.186)\end{array}$ & $\begin{array}{c}0.614 \\
(0.413)\end{array}$ & $\begin{array}{c}-2.344^{* *} \\
(1.099)\end{array}$ & $\begin{array}{c}0.060 \\
(0.605)\end{array}$ \\
\hline lnDist & $\begin{array}{c}-0.072 \\
(0.162)\end{array}$ & $\begin{array}{c}0.487^{* *} \\
(0.234)\end{array}$ & $\begin{array}{c}0.050 \\
(0.197)\end{array}$ & $\begin{array}{c}-0.494 \\
(0.365)\end{array}$ & $\begin{array}{c}-0.139 \\
(0.229)\end{array}$ & $\begin{array}{l}-0.050 \\
(0.179)\end{array}$ \\
\hline $\ln G D P$ & $\begin{array}{l}-0.025 \\
(0.116)\end{array}$ & $\begin{array}{l}-0.047 \\
(0.203)\end{array}$ & $\begin{array}{c}0.017 \\
(0.152)\end{array}$ & $\begin{array}{c}0.264 \\
(0.221)\end{array}$ & $\begin{array}{c}-0.138 \\
(0.153)\end{array}$ & $\begin{array}{l}-0.153 \\
(0.126)\end{array}$ \\
\hline $\operatorname{lnGDPpc}$ & $(0.291)$ & $\begin{array}{l}-0.366 \\
(0.471)\end{array}$ & $\begin{array}{l}-0.000 \\
(0.346)\end{array}$ & $\begin{array}{l}-0.035 \\
(0.538)\end{array}$ & $\begin{array}{c}-0.898^{*}-0.477 \\
(0.428)\end{array}$ & $\begin{array}{l}-0.485 \\
(0.348)\end{array}$ \\
\hline Constant & $\begin{array}{l}-2.328 \\
(5.195)\end{array}$ & $\begin{array}{c}-35.426^{* * *} \\
(7.757) \\
\end{array}$ & $\begin{array}{c}-14.641^{*} \\
(7.518) \\
\end{array}$ & $\begin{array}{l}-3.055 \\
(7.328)\end{array}$ & $\begin{array}{l}-6.678 \\
(7.715)\end{array}$ & $\begin{array}{c}-11.978^{* *} \\
(5.658)\end{array}$ \\
\hline $\begin{array}{l}\text { Country dummies } \\
\text { time dummies }\end{array}$ & $\begin{array}{l}\text { no } \\
\text { yes }\end{array}$ & $\begin{array}{l}\text { no } \\
\text { yes }\end{array}$ & $\begin{array}{l}\text { no } \\
\text { yes }\end{array}$ & $\begin{array}{l}\text { no } \\
\text { yes }\end{array}$ & $\begin{array}{l}\text { no } \\
\text { yes }\end{array}$ & $\begin{array}{l}\text { no } \\
\text { yes }\end{array}$ \\
\hline Industry dummies & no & no & no & no & no & no \\
\hline Log pse.likelihood & -840.6054 & -482.4536 & -777.3525 & -218.0989 & -640.9280 & -601.2528 \\
\hline Wald test & $\begin{array}{c}\operatorname{chi} 2(15)= \\
216.40^{* * *}\end{array}$ & $\begin{array}{c}\operatorname{chi} 2(15)= \\
150.31 * * *\end{array}$ & $\begin{array}{c}\operatorname{chi} 2(15)= \\
256.47 * * *\end{array}$ & $\begin{array}{l}\operatorname{chi} 2(15)= \\
43.70 * * *\end{array}$ & $\begin{array}{c}\operatorname{chi} 2(15)= \\
227.15^{* * *}\end{array}$ & $\begin{array}{c}\operatorname{chi} 2(15)= \\
126.39^{* * *}\end{array}$ \\
\hline \multicolumn{6}{|c|}{ Likelihood-ratio test; $r h o=0: \operatorname{chi} 2(1)($ Prob $>\operatorname{chi} 2)$} & $320.29 * * *$ \\
\hline Observations & 466,797 & 464,599 & 402,302 & 401,813 & 325,843 & 473,705 \\
\hline N. of firm-market-product & 298,982 & 299,737 & 255,663 & 257,763 & 216,485 & 295,521 \\
\hline
\end{tabular}

Note: Standard errors in parentheses; ${ }^{* * *} p<0.01,{ }^{* *} p<0.05,{ }^{*} p<0.1$.

with significantly positive coefficient for the interaction term. On the other hand, for the substitutes subsample we fail to find any significant effect for IPRs or its interaction with upstreamness on the likelihood of integration, which is also in line with the model prediction.

\section{Concluding Discussion}

In this paper we provided a theory supported by empirical evidence that reveal the presence of intangible assets in global supply chains and their importance for the organizational decision of firms. We adopt a strategy that considers heterogeneous stages of production along the supply chain in order to show the consequences of the risk of imitation. Assuming that it is those stages that are most susceptible to imitation that react most sharply to IPR protection, we test the impact 
of IPRs in the supplier locations on the integration decision of Slovenian firms. The findings suggest that intangible assets matter most at downstream stages and when stages along the supply chain are sequential complements. It is under such circumstances that better IPR institutions in supplier country encourage outsourcing over integration. The results are in line with models of supplier investment incentive structure, where integration is the default result for downstream stages under sequential complements.

A helpful point of comparison for our results is the effect of the degree of contractibility on the organizational mode along the supply chain (Alfaro et al., 2015). This argument explicitly refers to tangible assets. Starting from an incomplete contract environment, reducing the contract frictions initially introduced in the model under the property rights approach allows firms to rely less on outsourcing to compensate for distortions associated with inefficient upstream investment for sequential complements. Consequently, they reduce the set of outsourced stages on the upstream side of the chain, where outsourcing was previously necessary and prevalent. This would move the cut-off stage in Antràs and Chor (2013) to the left. The opposite should hold when inputs are sequential substitutes. The key conceptual distinction in our framework is that contract incompleteness is present at all times, but what changes is the possibility of imitation of intangible assets by outside competitors, itself determined by the degree of IPR protection in the supplier location. Introducing this feature produces two notable differences in our results.

The first evident point of departure from Antràs and Chor (2013) and Alfaro et al. (2015) is that the case of substitutable inputs is less relevant for the organizational choice of firms when dealing with intangible assets. Imitation erodes the dynamic effect of upstream investment on supplier incentives boosted by outsourcing rendering the firm indifferent about the two modes of organization. In technical terms, sensitivity of $\beta$ to changes in $\mu$ is decreasing in $\alpha$, that is, the more substitutable are the inputs. As a result, changes in the level of IPR protection should not significantly affect the propensity of firms to integrate. This argument also suggests that $\alpha$, as a real measure of physical or technological substitutability between stages, can be as relevant as the elasticity of demand $(\rho)$ to distinguish between sequential complements/substitutes, particularly when considering intangible assets.

The second divergence arises when looking into the case of complements, where imitation and IPRs do play a role in determining the organizational mode. In fact, we have seen above that when considering intangible assets, outsourcing is the organizational form that prevails for a wider range of production stages in case of stronger IPR protection. This is because imitation risk offsets the incentive channel and the positive effect of upstream investment created by outsourcing on subsequent stages. This is clearly in contrast to the effect of contract enforcement itself and how this liberalizes firms to enjoy a larger share of the revenues, not having the need to outsource in order to avert inefficient upstream investment. Imitation, on the contrary, blocks this channel of gains 
from outsourcing, making it optimal for the final good producer to forgo the incentive structure and integrate at an earlier stage. IPR protection reverts this decision and puts the Antràs and Chor (2013) mechanism back in place. Notice that the equilibrium restored by IPR protection is the equilibrium under incomplete contracts.

Finally, it is worth mentioning that in our modeling strategy, we have introduced imitation of intellectual property within the context of the property right theory so that it could occur under both outsourcing and integration. Recall first that the imitators in our model are in principle competitors outside the supply chain relationships, hence the organizational choice should not necessarily have an impact on the imitation risk. Nonetheless, if imitation were to be adopted using the transaction cost approach, so that integration could be used to internalize imitation risk and avoid technology leak to competitors that can be more likely under outsourcing, our main results persist and gain strength. This is because the results under both concepts go the same direction, and assuming that imitation is only viable under outsourcing is an extra constraint that would make integration more attractive under weak IPR protection. We get this result in the absence of such assumption, highlighting the role of imitation on firm organization through the incentive structure channel of supplier investment. This also mitigates concerns that firms could strategically select their location based on the IPR regime in the supplier location, making imitation endogenous in the organizational mode. As our empirical investigation encompasses a more general environment, we cannot detect whether the integration decision of firms stems from the supplier incentive structure or attempts to prevent the dissipation of their technology.

As avenues for future research, we would like to expand the model to allow for several destination countries, and thereby, include the location decision for each individual stage based on the strength of IPR institutions. A spider model in which a multinational simultaneously procures inputs from different locations prior to the assembly of its final product would perhaps be more suitable for this variant of the model. Empirically, while we use a number of rich databases the combination of which has allowed us to deal with a complex set of problems, limitations of the data impedes us from performing a more detailed analysis and from using a larger sample period. 


\section{References}

Alfaro, L., Antràs, P., Chor, D., Conconi, P. (2015), "Internalizing Global Value Chains: A FirmLevel Analysis", NBER Working Paper 21582, National Bureau of Economic Research.

Antràs, P. (2003), "Firms, Contracts, and Trade Structure", Quarterly Journal of Economics, 118 (4), 1375-1418.

Antràs, P. (2005), "Incomplete Contracts and the Product Cycle", American Economic Review, 95 (4), 1054-1073.

Antràs, P. (2014), "Grossman-Hart (1986) Goes Global: Incomplete Contracts, Property Rights, and the International Organization of Production", Journal of Law, Economics and Organization, 30 S1, i118-i174.

Antràs, P., Chor, D. (2013), "Organizing the Global Value Chain", Econometrica, 81 (6), 2127-2204.

Antràs, P., Chor, D., Fally, T., Hillberry, R. (2012), Measuring the Upstreamness of Production and Trade Flows", American Economic Review Papers and Proceedings, 102 (3), 412-416.

Antràs, P., Helpman, E. (2004), "Global Sourcing", Journal of Political Economy, 112 (3), 552-580.

Antràs, P., Helpman, E. (2008), "Contractual Frictions and Global Sourcing", in Helpman, E., D. Marin, and T. Verdier, eds., The Organization of Firms in a Global Economy, Cambridge, MA: Harvard University Press.

Antràs, P., Rossi-Hansberg, E. (2009), "Organizations and Trade", Annual Review of Economics, $1(1), 43-64$.

Atalay, E., Hortacsu, A., Syverson, C. (2014), "Vertical Integration and Input Flows", American Economic Review, 104 (4), 1120-1148.

Chamberlain, G. (1984): Panel data", in Handbook of Econometrics, Elsevier, ed. by Z. Griliches, and M. Intriligator, 1247-1318.

Corcos, G., Irac, D.M., Mion, G., Verdier, T. (2013), "The Determinants of Intra-Firm Trade", The Review of Economics and Statistics, 95(3), 825-838.

Defever, F., Toubal, F. (2013), "Productivity, Relation-Specific Inputs and the Sourcing Modes of Multinationals", Journal of Economic Behavior and Organization, 94, 245-357.

Eppinger, P., Kukharskyy, B. (2016), "Contracting Institutions and Firm Boundaries", University of Tuebingen, mimeo.

Fally, T. (2012), "On the Fragmentation of Production in the U.S.", University of Colorado-Boulder, mimeo.

Grossman, S. J., Hart, O. D. (1986), "The Costs and Benefits of Ownership: A Theory of Vertical and Lateral Integration", Journal of Political Economy, 94(4), 691-719.

Grossman, G. M., Helpman, E. (2002), "Integration vs. Outsourcing in Industry Equilibrium", Quarterly Journal of Economics, 117, 85-120.

Grossman, G.M., Helpman, E. (2003), "Outsourcing versus FDI in Industry Equilibrium", Journal of the European Economic Association, 1, 317-327. 
Grossman, G.M., Helpman, E. (2005), "Outsourcing in a Global Economy", Review of Economic Studies, 72, 135-159.

Hart, O. D., Moore, J. (1990), "Property Rights and the Nature of the Firm", Journal of Political Economy, 98(6), 1119-1158.

Kee, H.L., Nicita, A., Olarreaga, M. (2008), "Import Demand Elasticities and Trade Distortions", The Review of Economics and Statistics, 90(4), 666-682.

Mundlack, Y (1978), "On the Pooling of Time Series and Cross Section Data", Econometrica, 46(1), 69-85.

Olley, G.S., Pakes, A. (1996), "The Dynamics of Productivity in the Telecommunications Equipment Industry", Econometrica, 46(1), 1263-1297.

Park, W.G. (2008), "International Patent Protection: 1960-2005", Research Policy, 37, 761-766.

Pierce, J.R., Schott, P.K. (2009), "A Concordance Between Ten-Digit U.S. Harmonized System Codes and SIC/NAICS Product Classes and Industries", NBER Working Paper 15548, National Bureau of Economic Research.

United Nations Statistics Division (2009), "Note on HS 2007 data conversion in UN Comtrade", available at < https://unstats.un.org/unsd/trade/conversions/Note\%20on\%20the\%20HS\%202007\%20data \%20conversion\%20in\%20UN\%20Comtrade.pdf>, accessed on 15 January 2016.

Williamson, O. (1971), "The Vertical Integration of Production: Market Failure Considerations", American Economic Review, 61 (2), 112-123.

Williamson, O. (1975), Markets and Hierarchies: Analysis and Antitrust Implications, New York,NY: The Free Press.

Williamson, O. (1985), The Economic Institutions of Capitalism, New York,NY: The Free Press.

Wooldridge, J.M. (2012), Introductory Econometrics, Mason, OH: South-Western.

Worldwide Governance Indicators (2015), The World Bank Group, available at http://data.worldbank .org/data-catalog/worldwide-governance-indicators.

WTO (2012), World Trade Report 2016: Levelling the Trading Field for SMEs, Washington, DC: World Trade Organization.

Van Beveren, I., Bernard, A.B., Vandenbussche, H. (2012), "Concording EU Trade and Production Data over Time", NBER Working Paper 18604, National Bureau of Economic Research. 


\section{Appendix A: Mathematical Appendix}

\section{A-1. Derivation of program (6)}

This appendix reports some steps which lead to derive the theoretical results introduced and discussed in the main text. As explained in Section 3.3, from a pure mathematical standpoint, our variant of Antràs and Chor (2013) bears a resemblance of that of Alfaro et al. (2015), although the two papers focus on completely different aspects of the interaction between institutional environment and organization of a sequential production line. We therefore refer the reader to that paper (and to the original work of Antràs and Chor (2013), of course) for more technical details on the matter, herein restricting ourselves to highlight only the most relevant differences that characterize our framework with respect to theirs.

In deriving program (6) in Section 3.2, for instance, we follow the same procedure that Alfaro et al. (2015) use to derive program (8) in their body text. Hence, we first solve the supplier's problem, which consists of finding the optimal amount of investments, namely $x^{*}(z)$, that maximizes supplier $z$ 's surplus, i.e. $(1-\beta(z)) r^{\prime}(z)-c x(z)$, where $r^{\prime}(z)$ is the derivative in $z$ of the revenue function

$$
r(z)=A^{1-\rho} \theta^{\rho}\left(\int_{0}^{z}\left[e^{-\mu s} x(s)\right]^{\alpha} d s\right)^{\frac{\rho}{\alpha}}
$$

and therefore corresponds to

$$
r^{\prime}(z)=\frac{\rho}{\alpha}\left(A^{1-\rho} \theta^{\rho}\right)^{\frac{\alpha}{\rho}} \cdot[r(z)]^{\frac{\rho-\alpha}{\rho}} \cdot\left[e^{-\mu z} x(z)\right]^{\alpha}
$$

The optimal investment level for supplier $z$ can be proved to be

$$
x(z)=\left[(1-\beta(z)) \cdot \rho A^{\frac{(1-\rho) \alpha}{\rho}} \cdot e^{-\alpha \mu z}[r(z)]^{\frac{\rho-\alpha}{\rho}}\right]^{\frac{1}{1-\alpha}},
$$

which plugged into the above expression for $r^{\prime}(z)$ originates a separable differential equation for $r(z)$, namely

$$
r^{\prime}(z)=\frac{\rho}{\alpha}\left(A^{1-\rho}\right)^{\frac{\alpha}{\rho(1-\alpha)}} \cdot[r(z)]^{\frac{\rho-\alpha}{\rho(1-\alpha)}} \cdot\left[\rho(1-\beta(z)) e^{-\mu z}\right]^{\frac{\alpha}{1-\alpha}},
$$

with solution

$$
r(z)=A\left(\frac{1-\rho}{1-\alpha}\right)^{\frac{\rho(1-\alpha)}{\alpha(1-\rho)}} \rho^{\frac{\rho}{1-\rho}} \cdot\left[\int_{0}^{z}\left[(1-\beta(s)) e^{-\mu s}\right]^{\frac{\alpha}{1-\alpha}} d s\right]^{\frac{\rho(1-\alpha)}{\alpha(1-\rho)}}
$$

With this expression in mind, we now turn to the problem of the final good producer which is in control of the supply chain. This firm has to choose the optimal division of surplus at any stage of production, thereby solving the following profit-maximization program: $\max _{\beta(z)} \pi=\int_{0}^{1} \beta(z) \cdot r^{\prime}(z) d z$. 
By differentiating equation (A1), this program can be re-expressed as follows:

$$
\max _{\beta(z)} \pi=\Phi \int_{0}^{1} \beta(z)\left[e^{-\mu z}(1-\beta(z))\right]^{\frac{\alpha}{1-\alpha}}\left[\int_{0}^{z}\left[e^{-\mu s}(1-\beta(s))\right]^{\frac{\alpha}{1-\alpha}} d s\right]^{\frac{\rho-\alpha}{\alpha(1-\rho)}} d z
$$

where $\Phi \equiv A \cdot\left(\frac{1-\rho}{1-\alpha}\right)^{\frac{\rho-\alpha)}{\alpha(1-\rho)}} \rho^{\frac{\rho}{1-\rho}}$. This exactly corresponds to program (6) in Section 3.2.

\section{A-2. Optimal Ownership Structure for the Substitutes Case}

Following the same approach of Antràs and Chor (2013), we solve the firm's problem in our generalized framework by considering a relaxed version of program (6), in which the firm could freely choose the function $\beta(z)$ from the whole set of piece-wise continuously differentiable real-valued functions, rather than from those that only take on values in the set $\left\{\beta_{V}, \beta_{O}\right\}$. As in their paper, we reformulate the firm's problem in terms of $v(z)$, a real-valued function of $z$ defined as

$$
v(z) \equiv \int_{0}^{1}\left(e^{-\mu s}[1-\beta(s)]\right)^{\frac{\alpha}{1-\alpha}} d s
$$

The problem thus turns into a program of the type

$$
\max _{v(z), u(z)} \pi=\Phi \cdot \int_{0}^{1}\left[1-e^{\mu z} u(z)^{\frac{1-\alpha}{\alpha}}\right] \cdot u(z) \cdot v(z)^{\frac{\rho-\alpha}{\alpha(1-\rho)}} d v
$$

in which the control variable, denoted as $u(z)$, is

$$
u(z)=v^{\prime}(z)=\left[e^{-\mu z}(1-\beta(z))\right]^{\frac{\alpha}{1-\alpha}}
$$

The Euler-Lagrange equation associated leads to:

$$
\frac{1}{\alpha} e^{\mu z} u^{\frac{1-\alpha}{\alpha}} v^{\frac{\rho-\alpha}{\alpha(1-\rho)}} \cdot\left[\frac{(\rho-\alpha)(1-\alpha)}{\alpha(1-\rho)} \frac{u}{v}+\mu+\frac{1-\alpha}{\alpha} \frac{u^{\prime}}{u}\right]=0,
$$

where $v=v(z), u=u(z)=v^{\prime}$, and $u^{\prime}=v^{\prime \prime}$. Out of the three type of solutions that can be outlined for the above equation, only one generates strictly positive profits, namely

$$
\frac{(\rho-\alpha)(1-\alpha)}{\alpha(1-\rho)} \frac{u}{v}+\mu+\frac{1-\alpha}{\alpha} \frac{u^{\prime}}{u}=0
$$

The solution to this second-order differential equation is represented by a first-order differential equation, that is

$$
u(z)=v^{\prime}(z)=C_{1} e^{-\frac{\alpha}{1-\alpha} \mu z} v(z)^{\frac{\alpha-\rho}{1-\rho}}
$$

where $C_{1}$ is a positive constant, which embeds the constant of integration. 
The first-order differential equation has solution

$$
v(z)=\left[C_{2}-\frac{(1-\alpha)^{2} C_{1}}{\mu \alpha(1-\rho)} e^{-\frac{\alpha}{1-\alpha} \mu z}\right]^{\frac{1-\rho}{1-\alpha}},
$$

where $C_{2}$ is another constant term, inclusive of a second constant of integration.

To find the precise expression of $C_{1}$ and $C_{2}$, we impose (i) the initial condition, i.e. $v(0)=0$; and (ii) the transversality condition, i.e. $1-\frac{1}{\alpha} v^{\prime}(1)^{\frac{1-\alpha}{\alpha}} e^{\mu}=0$.

Indeed, by combining the initial condition with (A5) evaluated at $z=0$, we get $C_{2}=\frac{(1-\alpha)^{2}}{\alpha \mu(1-\rho)} C_{1}$. By combining the transversality condition with (A4) evaluated at $z=1$, we obtain

$$
C_{1}=\alpha^{\frac{\alpha}{1-\rho}}\left[\frac{(1-\alpha)^{2}}{\alpha \mu(1-\rho)}\right]^{\frac{\rho-\alpha}{1-\rho}}\left(1-e^{-\frac{\alpha}{1-\alpha} \mu}\right)^{\frac{\rho-\alpha}{1-\rho}}
$$

Given the expressions for $C_{1}$ and $C_{2}$, the value function $v(z)$ can then be written as follows:

$$
v(z)=\Lambda \cdot\left(1-e^{-\frac{\alpha}{1-\alpha} \mu z}\right)^{\frac{1-\rho}{1-\alpha}}
$$

where $\Lambda \equiv \alpha^{\frac{\alpha}{1-\alpha}} \frac{(1-\alpha)^{2}}{\mu \alpha(1-\rho)}\left(1-e^{-\frac{\alpha}{1-\alpha} \mu}\right)^{\frac{\rho-\alpha}{1-\alpha}}$. This implies

$$
v^{\prime}(z)=\alpha^{\frac{\alpha}{1-\alpha}}\left(\frac{1-e^{-\frac{\alpha}{1-\alpha} \mu z}}{1-e^{-\frac{\alpha}{1-\alpha} \mu}}\right)^{\frac{\alpha-\rho}{1-\alpha}} \cdot e^{-\frac{\alpha}{1-\alpha} \mu z}
$$

In the light of equation (A2), the optimal share at stage $z$ turns out to be:

$$
\beta^{*}(z)=1-\alpha \cdot\left(\frac{1-e^{-\frac{\alpha}{1-\alpha} \mu z}}{1-e^{-\frac{\alpha}{1-\alpha} \mu}}\right)^{\frac{\alpha-\rho}{\alpha}} .
$$

This solution can be proved to satisfy a sufficient condition for a maximum and can be also characterized as the solution of the firm's problem when $\beta^{*}(z)$ is constrained to take non-negative values. In the substitutes case $(\rho<\alpha)$, the solution to the unconstrained problem, given in (A8), does not violate the constraint $0 \leq \beta(z) \leq 1$; in fact, it can be proved that

$$
0 \leq 1-\alpha \cdot\left(\frac{1-e^{-\frac{\alpha}{1-\alpha} \mu z}}{1-e^{-\frac{\alpha}{1-\alpha} \mu}}\right)^{\frac{\alpha-\rho}{\alpha}} \leq 1
$$

holds for any $\rho \in(0,1)$ and for any $\alpha \in(0,1)$ such that $\rho<\alpha$. It follows than, exactly as in Antràs and Chor (2013) and Alfaro et al. (2015), the solution obtained from solving the unconstrained problem is necessarily also the one which yields the maximum for the constrained problem.

In Figure A1 of Appendix A-3, we plot the optimal share function (A8) for two arbitrary values of $\rho$ and $\alpha$, such that $\rho<\alpha$. The function is represented as downward-sloping solid line: in analogy with the baseline model, the (unconstrained) optimal share $\beta^{*}(z)$ is a decreasing function of $z$ whenever supplier investments are sequential substitutes (i.e. $\rho<\alpha$ ). 


\section{A-3. Optimal Ownership Structure for the Complements Case}

When $\rho>\alpha$, the optimal share generated by the function that solves the unconstrained problem, namely (A8), violates the constraint $0<\beta(z)<1$, since $\left[\left(1-e^{-\frac{\alpha}{1-\alpha} \mu z}\right) /\left(1-e^{-\frac{\alpha}{1-\alpha} \mu}\right)\right]^{\frac{\alpha-\rho}{\alpha}}>1$ for some values of $z \in[0,1]$. For the complements case $(\rho>\alpha)$, the solution to the firm's problem must therefore be obtained by solving the constrained version of problem, formulated as follows:

$$
\begin{array}{ll} 
& \max _{v(z), u(z)} \Phi \int_{0}^{1}\left[1-e^{\mu z} u(z)^{\frac{1-\alpha}{\alpha}}\right] \cdot u(z) \cdot v(z)^{\frac{\rho-\alpha}{\alpha(1-\rho)}} d v \\
\text { s.t. } \quad 0< & e^{\frac{\alpha}{1-\alpha} \mu z} u(z)<1 \\
v(0)=0 & \text { (initial condition) }
\end{array}
$$

where $z \in[0,1]$ and $v^{\prime}(z)=u(z)$, while $\Phi$ is the constant term introduced in Appendix A-1. As in the constrained problem, the optimal share at each of production is given by $\beta(z)=1-e^{\mu z} v^{\prime}(z)^{\frac{1-\alpha}{\alpha}}$.

The Hamiltonian function associated with this problem is therefore

$$
H(v, u, z, \lambda)=\left[1-e^{\mu z} u^{\frac{1-\alpha}{\alpha}}\right] \cdot u \cdot v^{\frac{\rho-\alpha}{\alpha(1-\rho)}}+\lambda u+\theta\left(1-e^{\frac{\alpha}{1-\alpha} \mu z} u\right)
$$

which implies the following costate equation: $\lambda^{\prime}=-\frac{\partial H}{\partial v}=-\frac{\rho-\alpha}{\alpha(1-\rho)} v^{\frac{\rho-\alpha}{\alpha(1-\rho)}}\left[1-e^{\mu z} u^{\frac{1-\alpha}{\alpha}}\right] \frac{u}{v}$.

At the same time, the first-order condition of the firm's problem, namely $\partial H / \partial u=0$, implies $\lambda=-v^{\frac{\rho-\alpha}{\alpha(1-\rho)}}\left(1-(1 / \alpha) e^{\mu z} u^{\frac{1-\alpha}{\alpha}}\right)+\theta e^{\frac{\alpha}{1-\alpha} \mu z} \cdot{ }^{11}$ According to this, the total derivative of $\lambda$ turns out to be:

$$
\lambda^{\prime}=-\frac{\rho-\alpha}{\alpha(1-\rho)} v^{\frac{\rho-\alpha}{\alpha(1-\rho)}}\left[1-\frac{1}{\alpha} e^{\mu z} u^{\frac{1-\alpha}{\alpha}}\right] \frac{u}{v}+\frac{1}{\alpha} e^{\mu z} u^{\frac{1-\alpha}{\alpha}} v^{\frac{\rho-\alpha}{\alpha(1-\rho)}}\left[\frac{1-\alpha}{\alpha} \frac{u^{\prime}}{u}+\mu\right]+F\left(z, \theta^{\prime}, \theta\right) .
$$

Putting together the above equation and the costate equation, one gets

$$
\frac{1-\alpha}{\alpha^{2}} e^{\mu z} u^{\frac{1-\alpha}{\alpha}} v^{\frac{\rho-\alpha}{\alpha(1-\rho)}}\left[\frac{\rho-\alpha}{1-\rho} \frac{u}{v}+\frac{u^{\prime}}{u}+\frac{\alpha}{1-\alpha} \mu\right]+F\left(z, \theta^{\prime}, \theta\right)=0
$$

When the constraint $u \leq 1$ (i.e. $\beta(z) \geq 0$ ) does not bite, then $\theta^{\prime}=\theta=0$ and equation (A9) delivers exactly the same second-order differential equation of the constrained problem, namely equation (A3), thus the solution is still $u=v^{\prime}(z)=C_{1} e^{-\frac{\alpha}{1-\alpha} \mu z} v(z)^{\frac{\alpha-\rho}{1-\rho}}$, i.e. equation (A4).

Notice that for $v(z)$ sufficiently small (in particular, in the neighborhood of $z=0$ ), and given $\rho>\alpha$, we necessarily have that $e^{\frac{\alpha}{1-\alpha} \mu z} v^{\prime}(z)>1$, which means that the constraint $e^{\frac{\alpha}{1-\alpha} \mu z} v^{\prime}(z) \leq 1$ must bind, implying $\theta>0$. The costate equation implies that $\lambda^{\prime}=0$. In light of the first-order condition $\partial H / \partial u=0$, this in turn implies that $\theta$ is a monotonically decreasing function of $z$ as

\footnotetext{
${ }^{11}$ Notice that this equation for $\lambda$ delivers the transversality condition for this problem. Provided that the constraint does not bind in $z=1$, which implies $\theta=0$ in that point, $\lambda(1)$ has to be equal to 0 . With some simple algebra we can therefore derive the transversality condition for this problem, which is $v^{\prime}(1)^{\frac{1-\alpha}{\alpha}} e^{\mu}=\alpha$.
} 
long as the constraint binds. We can conclude that, if the constraint binds at some point $\widehat{z} \in(0,1)$, then it necessarily binds (i.e. $\theta>0$ ) for any $z<\widehat{z}$. Hence, we have $e^{\frac{\alpha}{1-\alpha} \mu z} v^{\prime}(z)=1$, which means $\beta(z)=0$ for all $z \in[0, \widehat{z}]$.

Moreover, we can write $v(\widehat{z}) \equiv \int_{0}^{\widehat{z}} v^{\prime}(z) d z=\int_{0}^{\widehat{z}} u(z) d z$, which leads to

$$
v(\widehat{z})=\frac{1-\alpha}{\alpha \mu}\left[1-e^{-\frac{\alpha}{1-\alpha} \mu \widehat{z}}\right]
$$

With this expression in hand, we can now solve the first-order differential equation, represented by (A4), albeit limited to $z>\widehat{z}$. The solution is still

$$
v(z)=\left[C_{2}-\frac{(1-\alpha)^{2} C_{1}}{\mu \alpha(1-\rho)} e^{-\frac{\alpha}{1-\alpha} \mu z}\right]^{\frac{1-\rho}{1-\alpha}}
$$

which is the same equation as (A4). The derivative of $v(z)$ with respect to $z$ is

$$
v^{\prime}(z)=C_{1} e^{-\frac{\alpha}{1-\alpha} \mu z} \cdot\left[C_{2}-\frac{(1-\alpha)^{2} C_{1}}{\mu \alpha(1-\rho)} e^{-\frac{\alpha}{1-\alpha} \mu z}\right]^{\frac{\alpha-\rho}{1-\alpha}}
$$

By combining equation (A11), evaluated at $z=1$, with the transversality condition, one obtains a first expression for the constant term $C_{2}$. An alternative expression can be derived by combining (A11), evaluated at $z=\widehat{z}$ with the boundary condition, namely $e^{\frac{\alpha}{1-\alpha} \mu \widehat{z}} v^{\prime}(\widehat{z})=1$. The two expressions, assembled together, lead us to write the constant term $C_{1}$ as follows

$$
C_{1}=\left[\frac{1}{1-\alpha^{-\frac{\alpha}{\rho-\alpha}}} \cdot \frac{(1-\alpha)^{2}}{\mu \alpha(1-\rho)}\left(e^{-\frac{\alpha}{1-\alpha} \mu}-e^{-\frac{\alpha}{1-\alpha} \mu \widehat{z}}\right)\right]^{\frac{\rho-\alpha}{1-\rho}} .
$$

We now use equation (A10). If combined with (A11) evaluated at $z=\widehat{z}$, this equation delivers a new expression for $C_{1}$, namely

$$
C_{1}=\left(\frac{1-\alpha}{\alpha \mu}\right)^{\frac{\rho-\alpha}{1-\rho}}\left[1-e^{-\frac{\alpha}{1-\alpha} \mu \widehat{z}}\right]^{\frac{\rho-\alpha}{1-\rho}}
$$

Equations (A12) and (A13), assembled together, allows for identifying stage $\widehat{z}$, based on the following equation:

$$
e^{-\frac{\alpha}{1-\alpha} \mu \widehat{z}}=\frac{e^{-\frac{\alpha}{1-\alpha} \mu}-\left(1-\alpha^{-\frac{\alpha}{\rho-\alpha}}\right)^{\frac{1-\alpha}{1-\rho}}}{1-\left(1-\alpha^{-\frac{\alpha}{\rho-\alpha}}\right)^{\frac{1-\alpha}{1-\rho}}} .
$$

Plugging equations (A14), (A13), (A12) and the expression for $C_{2}$ into (A11), we can finally derive the optimal share function $\beta^{*}(z)$ for all $z>\widehat{z}$, that is

$$
\beta^{*}(z)=1-\alpha\left[1+\chi \cdot \frac{e^{-\frac{\alpha}{1-\alpha} \mu}-e^{-\frac{\alpha}{1-\alpha} \mu z}}{e^{-\frac{\alpha}{1-\alpha} \mu}-1}\right]^{\frac{\alpha-\rho}{\alpha}} \quad, \text { where } \chi \equiv \frac{(1-\rho)\left(1-\alpha^{-\frac{\alpha}{\rho-\alpha}}\right)-(1-\alpha)}{(1-\rho) \alpha^{-\frac{\alpha}{\rho-\alpha}}}
$$


Hence, the solution to the constrained problem, which solve the firm's (relaxed) problem in the complements case (i.e. when $\rho>\alpha$ ) is:

$$
\beta^{*}(z)=\max \left\{0,1-\alpha\left[1+\chi \cdot \frac{e^{-\frac{\alpha}{1-\alpha} \mu}-e^{-\frac{\alpha}{1-\alpha} \mu z}}{e^{-\frac{\alpha}{1-\alpha} \mu}-1}\right]^{\frac{\alpha-\rho}{\alpha}}\right\}
$$

In Figure A1, the above solution (solid line, downward-sloping) is plotted together with the solutions to the unconstrained problem for the case $\rho>\alpha$ (dotted line) and $\rho<\alpha$ (solid line, upward-sloping). As in Antràs and Chor (2013), the optimal share $\beta^{*}(z)$ is a decreasing function of $z$ as long as supplier investments are sequential substitutes (i.e. $\rho<\alpha$ ). Moreover, as in their paper, $\beta^{*}(z)$ in the unconstrained problem is higher than in the constrained problem for all stages $z>\widehat{z}$ : when upstream suppliers cannot be incentivized by offering them a payoff exceeding their marginal contribution (as it would be optimal, if the constraint were absent), then the firm finds optimal to offer (i) full marginal contribution to a larger measure of suppliers, and (ii) a higher share of their marginal contribution to the remaining suppliers.

Figure A1: Profit-maximizing division of surplus for stage $z$ for the generalized model.

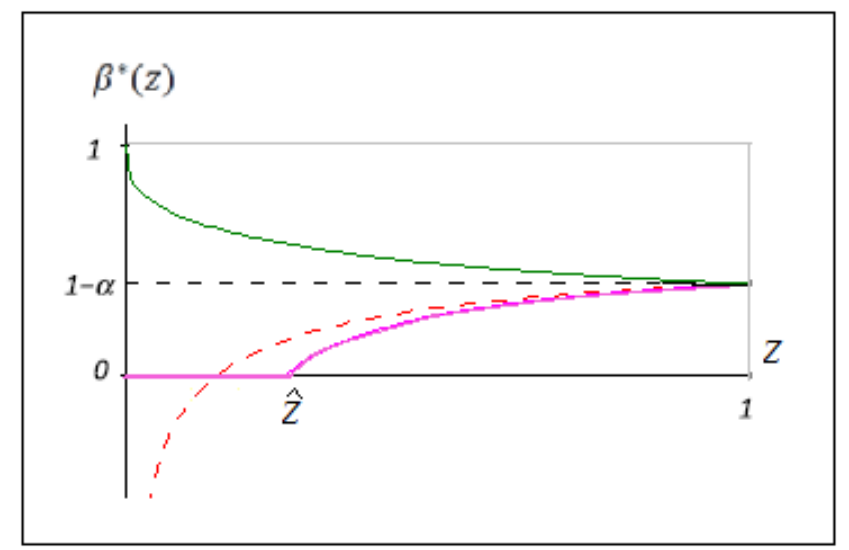

\section{A-4. Cut-off Stages and Proof of Propositions 1 and 2}

Propositions 1 and 2 can be proved by considering a particular case of the proof outlined by Alfaro et al. (2015) for their Proposition 2, which basically generalizes the proof of Proposition 2 in Antràs and Chor (2013). Indeed, they introduce asymmetries in the marginal product of different inputs' investments (in their case, induced by the different relative contractability of upstream stages versus downstream stages) by means of a stage-specific attribute, namely $\psi(i)$ (where $i$ indexes the stages of production, instead of $z$ ). In our framework, $\psi(z)$ takes on a particular interpretation as a discount factor for the value of suppliers investments, motived by the exposure to the risk of the final-good variety being imitated, with a potential loss from imitation that increases over $z$. Hence, we can 
follow the same procedure sketched in their Appendix A-1.3, setting $\psi(z)=e^{-\mu z}$ and abstracting away from heterogeneity in the marginal cost of production across stages.

Consider first the complements case $(\rho>\alpha)$. Given the solution reported in (A15), outsourcing will prevail at the very beginning of the supply chain, since $\beta^{*}(z)=0$ for all stages $z \in[0, \widehat{z}]$ and $\beta_{O}$ is lower than $\beta_{V}$. Since the most upstream stages are outsourced, stages to be integrated, if any, will necessarily be located downstream relative to those that are outsourced, which means that it does exist a cut-off stage $z_{C}^{*} \in(0,1]$, such that all stages $z \in\left[0, z_{C}^{*}\right)$ will be outsourced, whereas all stages $z \in\left[z_{C}^{*}, 1\right]$ will be integrated integrated within the firm's boundaries. Outsourcing and integration will coexist along the production line, conditional on $z_{C}^{*} \neq 1$; otherwise, the whole production process is outsourced.

The existence of this cut-off stage can be established by contradiction, following the line of reasoning of Alfaro et al. (2015), thus by considering the case of a stage $\widetilde{z} \in(0,1)$, such that the firm decides to integrate in the upstream neighborhood of $\widetilde{z}$, and to outsource in the downstream neighborhood of $\widetilde{z}$, thereby violating the pattern described in Proposition 1. Also in our case, it can be proved that this ownership structure would yield lower profits than an alternative organizational mode, such that outsourcing would apply to measurable set of stages located upstream than $\widetilde{z}$, and integration would apply to a measurable set of downstream stages, with the same organizational decision retained for all other stages (consistently with Proposition 1). Hence, deviating from the pattern described in Figure 4 would simply be inconsistent with the principle of profit maximization.

Similar arguments apply also in the substitutes case $(\rho<\alpha)$, to fully establish Proposition 2. In this case, the solution to the firm's problem is represented by the function in (A8). Since $\beta^{*}(z)$ takes value 1 at $z=0$ and then it monotonically decreases, it stands to reason that integration will be the preferred option at the very beginning of the value chain, given $\beta_{V}>\beta_{O}$. The optimal organizational structure is such that we cannot have a positive measure of outsourced stages located upstream relative to the measure of integrated stages. Hence, there exists a cut-off stage $z_{S}^{*} \in(0,1]$, such that integration occurs at all stages $z \in\left[0, z_{S}^{*}\right)$, while outsourcing occurs at all stages $z \in\left[z_{S}^{*}, 1\right]$. If $z_{S}^{*} \neq 1$, then the two organizational modes will coexist along the supply chain, preventing from full integration. The formal proof of Proposition 2 can be obtained by following the same approach hinted for Proposition 1.

To pin down the level of the cut-offs $z_{C}^{*}$ and $z_{S}^{*}$, we proceed as follows. Consider the realvalued function $\widetilde{v}(z) \equiv\left[\int_{0}^{z}\left[e^{-\mu s}(1-\beta(s))\right]^{\frac{\alpha}{1-\alpha}} d s\right]^{\frac{(1-\alpha) \rho}{\alpha(1-\rho)}}$ and its derivative with respect to $z$, namely $\partial \widetilde{v}(z) / \partial z=\frac{\rho(1-\alpha)}{\alpha(1-\rho)} \cdot\left[e^{-\mu z} 1-\beta(z)\right]^{\frac{\alpha}{1-\alpha}} \cdot\left[\int_{0}^{z}\left[e^{-\mu s}(1-\beta(s))\right]^{\frac{\alpha}{1-\alpha}} d s\right]^{\frac{\rho-\alpha}{\alpha(1-\rho)}}$.

Given this expression, the firm's profit function in (6) can be re-written as

$$
\pi=\frac{\alpha(1-\rho)}{\rho(1-\alpha)} \Phi \cdot \int_{0}^{1} \beta(z) \cdot \frac{\partial \widetilde{v}(z)}{\partial z} d z
$$


In the complements case $(\rho>\alpha)$, Proposition 1 implies that (A16) corresponds to

$$
\begin{aligned}
& \pi=\Phi \cdot \frac{\alpha(1-\rho)}{\rho(1-\alpha)} \beta_{O} \cdot\left(1-\beta_{O}\right)^{\frac{\rho}{1-\rho}}\left[\int_{0}^{z_{C}^{*}} e^{-\frac{\alpha}{1-\alpha} \mu s} d s\right]^{\frac{\rho(1-\alpha)}{\alpha(1-\rho)}}+ \\
& +\Phi \cdot \frac{\alpha(1-\rho)}{\rho(1-\alpha)} \beta_{V} \cdot\left[\left(1-\beta_{O}\right)^{\frac{\alpha}{1-\alpha}} \int_{0}^{z_{C}^{*}} e^{-\frac{\alpha}{1-\alpha} \mu s} d s+\left(1-\beta_{V}\right)^{\frac{\alpha}{1-\alpha}} \int_{z_{C}^{*}}^{1} e^{-\frac{\alpha}{1-\alpha} \mu s} d s\right]^{\frac{\rho(1-\alpha)}{\alpha(1-\rho)}}+ \\
& -\Phi \cdot \frac{\alpha(1-\rho)}{\rho(1-\alpha)} \beta_{V} \cdot\left[\left(1-\beta_{O}\right)^{\frac{\alpha}{1-\alpha}} \int_{0}^{z_{C}^{*}} e^{-\frac{\alpha}{1-\alpha} \mu s} d s\right]^{\frac{\rho(1-\alpha)}{\alpha(1-\rho)}} .
\end{aligned}
$$

If we maximize $\pi$ with respect to $z_{C}^{*}$, from the first-order condition of the problem we obtain

$$
\frac{\int_{0}^{z_{C}^{*}} e^{-\frac{\alpha}{1-\alpha} \mu s} d s}{\int_{0}^{1} e^{-\frac{\alpha}{1-\alpha} \mu s} d s}=\left\{1+\left(\frac{1-\beta_{O}}{1-\beta_{V}}\right)^{\frac{\alpha}{1-\alpha}}\left[\left(\frac{1-\frac{\beta_{O}}{\beta_{V}}}{1-\left(\frac{1-\beta_{O}}{1-\beta_{V}}\right)^{-\frac{\alpha}{1-\alpha}}}\right)^{\frac{\alpha(1-\rho)}{\rho-\alpha}}-1\right]\right\}^{-1}
$$

Notice that the condition for $z_{C}^{*}$ to be in the interval $(0,1)$ is the same as in the baseline model of Antràs and Chor $(2013)$, namely $\beta_{V}\left(1-\beta_{V}\right)^{\frac{\alpha}{1-\alpha}}>\beta_{O}\left(1-\beta_{O}\right)^{\frac{\alpha}{1-\alpha}}$ (which is the condition for the right-hand-side of equation (A17) to be lower than one). Hence, the degree of appropriability of intellectual assets does not play any role in determining whether outsourcing and integration coexist along the production line.

With some simple algebra, the cut-off stage can be proved to be

$z_{C}^{*}=\frac{\alpha-1}{\alpha \mu} \log \left(1+\frac{e^{-\frac{\alpha}{1-\alpha} \mu}-1}{\Omega_{C}}\right)$, with $\Omega_{C} \equiv 1+\left(\frac{1-\beta_{O}}{1-\beta_{V}}\right)^{\frac{\alpha}{1-\alpha}}\left[\left(\frac{1-\frac{\beta_{O}}{\beta_{V}}}{1-\left(\frac{1-\beta_{O}}{1-\beta_{V}}\right)^{-\frac{\alpha}{1-\alpha}}}\right)^{\frac{\alpha(1-\rho)}{\rho-\alpha}}-1\right]$

Consider now the substitutes case $(\rho<\alpha)$. In the light of Proposition 2, the profit function (A16) can be re-written in a specular way with respect to the case of sequential complements (with $\beta_{O}$ instead of $\beta_{V}$, and vice versa) and the first-order condition with respect to $z_{S}^{*}$ delivers the following counterpart of equation (A17):

$$
\frac{\int_{0}^{z_{S}} e^{-\frac{\alpha}{1-\alpha} \mu s} d s}{\int_{0}^{1} e^{-\frac{\alpha}{1-\alpha} \mu s} d s}=\left\{1+\left(\frac{1-\beta_{V}}{1-\beta_{O}}\right)^{\frac{\alpha}{1-\alpha}}\left[\left(\frac{\frac{\beta_{V}}{\beta_{O}}-1}{\left.\frac{1-\beta_{V}}{1-\beta_{O}}\right)^{-\frac{\alpha}{1-\alpha}}-1}\right)^{\frac{\alpha(1-\rho)}{\rho-\alpha}}-1\right]\right\}^{-1}
$$

Also in this case the condition for $z_{S}^{*}$ to be in the interval $(0,1)$ is not affected by $\mu$, this condition being $\beta_{V}\left(1-\beta_{V}\right)^{\frac{\alpha}{1-\alpha}}<\beta_{O}\left(1-\beta_{O}\right)^{\frac{\alpha}{1-\alpha}}$. The cut-off stage $z_{S}^{*}$ turns out to be

$$
z_{C}^{*}=\frac{\alpha-1}{\alpha \mu} \log \left(1+\frac{e^{-\frac{\alpha}{1-\alpha} \mu}-1}{\Omega_{S}}\right), \text { with } \Omega_{S} \equiv 1+\left(\frac{1-\beta_{V}}{1-\beta_{O}}\right)^{\frac{\alpha}{1-\alpha}}\left[\left(\frac{\frac{\beta_{V}}{\beta_{O}}-1}{\left(\frac{1-\beta_{V}}{1-\beta_{O}}\right)^{-\frac{\alpha}{1-\alpha}}-1}\right)^{\frac{\alpha(1-\rho)}{\rho-\alpha}}-1\right]
$$




\section{A-5. Proof of Proposition 3}

We conclude this Appendix with a proof of Proposition 3, which entails re-considering equation (A8), i.e. the solution to the firm's relaxed problem, in its unconstrained version:

$$
\beta^{*}(z)=1-\alpha \cdot\left(\frac{1-e^{-\frac{\alpha}{1-\alpha} \mu z}}{1-e^{-\frac{\alpha}{1-\alpha} \mu}}\right)^{\frac{\alpha-\rho}{\alpha}}
$$

The derivative of $\beta^{*}(z)$ with respect to $\mu$ turns out to be

$$
\frac{\partial \beta^{*}(z)}{\partial \mu}=\frac{\alpha}{1-\alpha}(\rho-\alpha) \cdot\left(\frac{1-e^{-\frac{\alpha}{1-\alpha} \mu z}}{1-e^{-\frac{\alpha}{1-\alpha} \mu}}\right)^{\frac{\alpha-\rho}{\alpha}} \frac{e^{-\frac{\alpha}{1-\alpha} \mu z}}{1-e^{-\frac{\alpha}{1-\alpha} \mu z}} \cdot\left[1-\frac{\left(1-e^{-\frac{\alpha}{1-\alpha} \mu z}\right) e^{-\frac{\alpha}{1-\alpha} \mu}}{\left(1-e^{-\frac{\alpha}{1-\alpha} \mu}\right) e^{-\frac{\alpha}{1-\alpha} \mu z}}\right] .
$$

The image of the entire domain $z \in[0,1]$ of both the derivative and the primitive function is either defined over the co-domain $\mathbb{R}^{+}$or $\mathbb{R}^{-}$, depending on the sign of $\alpha-\rho$. To make a meaningful comparison among the impact of IPR (i.e. $\mu$ ) on $\beta^{*}(z)$ in the two cases of complements and substitutes, we consider the absolute value of the above derivative, for a given absolute difference between parameter $\alpha$ (the degree of physical input substitutability) and parameter $\rho$ (the demand elasticity for the final-good variety).

Let $\epsilon$ be the absolute value of this difference, namely $\epsilon=|\alpha-\rho|$.

Hence, for a given value of $\epsilon$, supplier investments are sequential complements if $\alpha-\rho=\epsilon$; and complements if $\alpha-\rho=-\epsilon$. In the substitutes case, the derivative of $\beta^{*}(z)$ with respect to $\mu$ can therefore be written as

$$
\begin{gathered}
\left|\frac{\partial \beta^{*}(z)}{\partial \mu}\right|_{\alpha-\rho=\epsilon}=\left|-\epsilon \cdot \frac{\alpha}{1-\alpha} \cdot\left(\frac{1-e^{-\frac{\alpha}{1-\alpha} \mu z}}{1-e^{-\frac{\alpha}{1-\alpha} \mu}}\right)^{\frac{\epsilon}{\alpha}} \frac{e^{-\frac{\alpha}{1-\alpha} \mu z}}{1-e^{-\frac{\alpha}{1-\alpha} \mu z}} \cdot\left[1-\frac{\left(1-e^{-\frac{\alpha}{1-\alpha} \mu z}\right) e^{-\frac{\alpha}{1-\alpha} \mu}}{\left(1-e^{-\frac{\alpha}{1-\alpha} \mu}\right) e^{-\frac{\alpha}{1-\alpha} \mu z}}\right]\right|= \\
\quad=\epsilon \cdot \frac{\alpha}{1-\alpha} \cdot\left(\frac{1-e^{-\frac{\alpha}{1-\alpha} \mu z}}{1-e^{-\frac{\alpha}{1-\alpha} \mu}}\right)^{\frac{\epsilon}{\alpha}} \frac{e^{-\frac{\alpha}{1-\alpha} \mu z}}{1-e^{-\frac{\alpha}{1-\alpha} \mu z}} \cdot\left[1-\frac{\left(1-e^{-\frac{\alpha}{1-\alpha} \mu z}\right) e^{-\frac{\alpha}{1-\alpha} \mu}}{\left(1-e^{-\frac{\alpha}{1-\alpha} \mu}\right) e^{-\frac{\alpha}{1-\alpha} \mu z}}\right]
\end{gathered}
$$

whereas the counterpart for the complements case is

$$
\begin{gathered}
\left|\frac{\partial \beta^{*}(z)}{\partial \mu}\right|_{\alpha-\rho=-\epsilon}=\left|\frac{\alpha}{1-\alpha} \cdot \epsilon \cdot\left(\frac{1-e^{-\frac{\alpha}{1-\alpha} \mu z}}{1-e^{-\frac{\alpha}{1-\alpha} \mu}}\right)^{-\frac{\epsilon}{\alpha}} \frac{e^{-\frac{\alpha}{1-\alpha} \mu z}}{1-e^{-\frac{\alpha}{1-\alpha} \mu z}} \cdot\left[1-\frac{\left(1-e^{-\frac{\alpha}{1-\alpha} \mu z}\right) e^{-\frac{\alpha}{1-\alpha} \mu}}{\left(1-e^{-\frac{\alpha}{1-\alpha} \mu}\right) e^{-\frac{\alpha}{1-\alpha} \mu z}}\right]\right|= \\
=\epsilon \cdot \frac{\alpha}{1-\alpha} \cdot\left(\frac{1-e^{-\frac{\alpha}{1-\alpha} \mu}}{1-e^{-\frac{\alpha}{1-\alpha} \mu z}}\right)^{\frac{\epsilon}{\alpha}} \frac{e^{-\frac{\alpha}{1-\alpha} \mu z}}{1-e^{-\frac{\alpha}{1-\alpha} \mu z}} \cdot\left[1-\frac{\left(1-e^{-\frac{\alpha}{1-\alpha} \mu z}\right) e^{-\frac{\alpha}{1-\alpha} \mu}}{\left(1-e^{-\frac{\alpha}{1-\alpha} \mu}\right) e^{-\frac{\alpha}{1-\alpha} \mu z}}\right] .
\end{gathered}
$$

It is straightforward to show that

$$
\left|\frac{\partial \beta^{*}(z)}{\partial \mu}\right|_{\alpha-\rho=-\epsilon}>\left|\frac{\partial \beta^{*}(z)}{\partial \mu}\right|_{\alpha-\rho=\epsilon}
$$


Indeed, the above inequality holds for

$$
\left(\frac{1-e^{-\frac{\alpha}{1-\alpha} \mu}}{1-e^{-\frac{\alpha}{1-\alpha} \mu z}}\right)^{\frac{\epsilon}{\alpha}}>\left(\frac{1-e^{-\frac{\alpha}{1-\alpha} \mu z}}{1-e^{-\frac{\alpha}{1-\alpha} \mu}}\right)^{\frac{\epsilon}{\alpha}}
$$

which, in turns, implies $e^{-\frac{\alpha}{1-\alpha} \mu z}>e^{-\frac{\alpha}{1-\alpha} \mu}$. Given $\alpha \in(0,1)$, the last condition is verified as far as $z<1$, which is always true since $z \in[0,1]$.

We can therefore conclude that, for a given absolute difference between parameters $\alpha$ and $\rho$, the optimal share $\beta^{*}(z)$ is more sensitive to changes in $\mu$ (the strength of IPR enforcement) in the complements case $(\alpha-\rho=-\epsilon)$ rather than in the substitutes case $(\alpha-\rho=\epsilon)$, as stated in Proposition 3. 


\section{Appendix B: Data Appendix}

Table B1: The GVC participation index, Slovenia 2011 (\% share in total gross exports).

\begin{tabular}{lccc}
\hline & Slovenia & $\begin{array}{c}\text { Developing } \\
\text { countries }\end{array}$ & $\begin{array}{c}\text { Developed } \\
\text { countries }\end{array}$ \\
\hline Total GVC participation & 58.7 & 48.6 & 48.0 \\
Forward participation & 22.6 & 23.1 & 24.2 \\
Backward participation & 36.1 & 25.5 & 23.8 \\
\hline
\end{tabular}

Source: WTO.

Figure B1: The value-added (VA) components of gross exports, Slovenia 1995 and 2011. (\% share in total gross export)

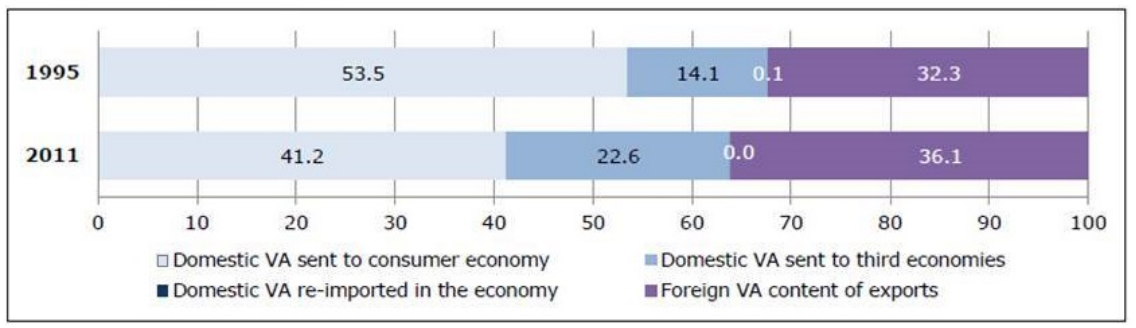

Source: WTO.

Figure B2: Slovenian FDI stock (\% of GDP)

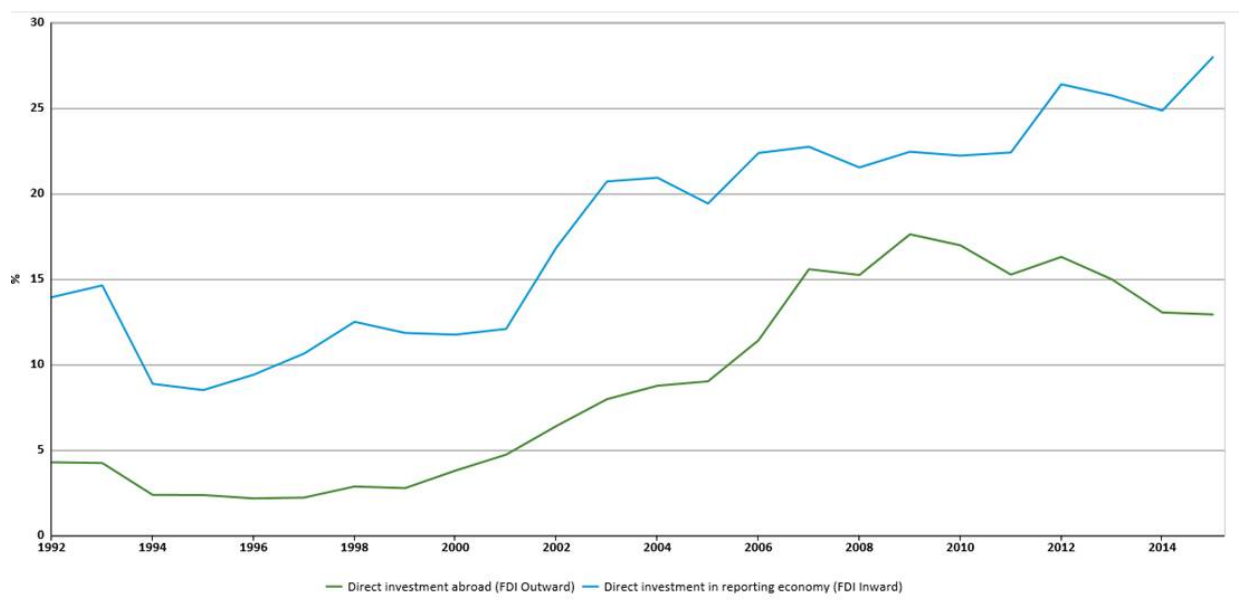

Source: WTO. 


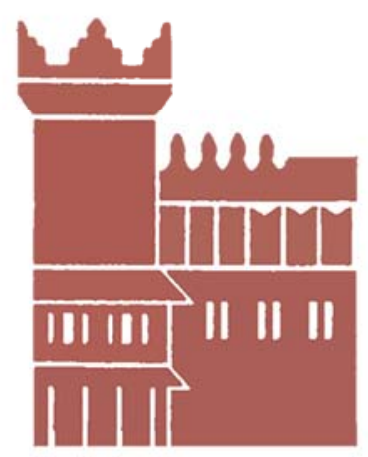

Alma Mater Studiorum - Università di Bologna DEPARTMENT OF ECONOMICS

Strada Maggiore 45

40125 Bologna - Italy

Tel. +39051 2092604

Fax +390512092664

http://www.dse.unibo.it 